\title{
Adaptive and Online Health Monitoring System for Autonomous Aircraft
}

\author{
Maizura Mokhtar, ${ }^{*}$ Sergio Z. Bayo ${ }^{\dagger}$ and Saed Hussain ${ }^{\ddagger}$ \\ University of Central Lancashire, Preston, PR1 2HE, UK. \\ Joe M. Howe ${ }^{\S}$ \\ University of Central Lancashire, Preston, PR1 2HE, UK.
}

\begin{abstract}
Good situation awareness is one of the key attributes required to maintain safe flight, especially for an Unmanned Aerial System (UAS). Good situation awareness can be achieved by incorporating an Adaptive Health Monitoring System (AHMS) to the aircraft. The AHMS monitors the flight outcome or flight behaviours of the aircraft based on its external environmental conditions and the behaviour of its internal systems. The AHMS does this by associating a health value to the aircraft's behaviour based on the progression of its sensory values produced by the aircraft's modules, components and/or subsystems. The AHMS indicates erroneous flight behaviour when a deviation to this health information is produced. This will be useful for a UAS because the pilot is taken out of the control loop and is unaware of how the environment and/or faults are affecting the behaviour of the aircraft. The autonomous pilot can use this health information to help produce safer and securer flight behaviour or fault tolerance to the aircraft. This allows the aircraft to fly safely in whatever the environmental conditions. This health information can also be used to help increase the endurance of the aircraft. This paper describes how the AHMS performs its capabilities.
\end{abstract}

Keywords: adaptive health monitoring system, UAS, endurance

\section{Introduction}

$\mathrm{N}_{\mathrm{N}}$ aircraft is one of the greatest engineering system created by man. An aircraft is also one of the most Adangerous and expensive system to make, operate and maintain. Failure to an aircraft not only results in the losses of lives of the people on-board but also of those at the location of impact. Therefore, safety is key.

\section{A. Unmanned Aerial System or UAS}

With the development of unmanned aerial system or UAS, we are taking the pilot out of the cockpit. This increases the risk much further.

UAS can be divided into three types:

1. Drones or autonomous aircraft: a UAS that is flown by an airborne intelligent flight systems.

2. Remotely piloted vehicle or RPV: a UAS that is actively flown remotely by the ground control operator.

3. Combined controls: a UAS's autonomous capabilities are provided by the Pilot Authority and Control of Task (PACT) concept, a concept in which the authority for the control is determined both by negotiation in the interest of mission objectives and by pre-emptive or time-sensitive actions in the interest of safety 1 !

*Post Doctoral Research Assistant, School of Computing, Engineering and Physical Sciences.

†Undergraduate Intern, School of Computing, Engineering and Physical Sciences

$\ddagger$ PhD Student, School of Computing, Engineering and Physical Sciences

$\S$ Professor, School of Computing, Engineering and Physical Sciences.

$$
1 \text { of } 25
$$


All these types of UAS require not only a good autonomous controller or a human operator to control the flight behaviour of the aircraft, but also good situation awareness or the ability to understand the conditions of the aircraft, be it its internal conditions and the (external) environment conditions that the aircraft is flying in. The issue with situation awareness for UAS is, the operator and/or the autonomous controller will only rely on the output provided by the sensors in order to produce the required behaviours. The natural instinct of the pilot that helps inform decision is loss when the pilot is placed outside of the control loop.

\section{B. Situation awareness}

Good situation awareness is therefore key in providing for safer flight behaviours for UAS. Good situation awareness provides for the ability to produce optimal flight outcome based on the information gathered regarding the conditions of the aircraft. An aircraft with good situation awareness will not only knows (understands) of the conditions it is flying in and the conditions of the aircraft itself (mechanical capabilities), but understand how these conditions affect its flight behaviour. Therefore, an aircraft with good situation awareness is key to maintain safe and secure flight behaviours.

Furthermore, good situation awareness can also help increase the endurance of the aircraft; with endurance defined as the ability to exert its capabilities for longer period of time.

\section{Adaptive Health Monitoring System}

An Adaptive Health Monitoring System (AHMS) is proposed to help provide for such capabilities. An adaptive health monitoring system differs from the traditional fault tolerance flight controller (FTFC) because the AHMS aims to:

1. Inform the pilot of any errors within the aircraft that can cause erroneous flight behaviours or fault detection and identification. AHMS performs fault detection and identification based on the progression of its sensors and actuators values during flight. Traditional FTFC uses mathematical model of errors to detect the errors.

2. Accommodate for the detected error by adjusting flight behaviours (flight controller output) based on its previous safe behaviour. Traditional FTFC uses estimated (mathematical model of the) sensors/actuators values to replace the detected error.

3. Be capable of integrating with existing flight management system (FMS), hence improving the flight controller output produced by the FMS.

The AHMS aims to achieve its objectives by:

1. Monitoring the various parts/systems within the aircraft as well as its flight behaviours and associating a health indicator to the aircraft

2. Instigating the need to compensate for any detected erroneous flight behaviour (fault tolerance), detected based on the deviation of the health value.

3. Identifying and providing the best flight controller output for compensation.

These functionalities aims to ensure safer, securer and efficient flight behaviours are produced irrespectively.

This paper, therefore, describes how the AHMS achieve its objectives, most specifically when the aircraft is flying in bad weather conditions. This paper is divided as follows: Section II describes what is the AHMS, how it differs from the traditional FTFC and how the AHMS can help improve flight behaviours. Section III describes the flight simulator used for the experiments and how the AHMS is integrated with the provided flight controller in the simulator. Section IV] describes the experiments that were carried out to test the capabilities of the AHMS. Section $\mathrm{V}$ describes and discusses the results of the experiments. Section VI concludes this paper.

\section{Adaptive Health Monitoring System or AHMS}

The Adaptive Health Monitoring System (AHMS) helps provide further information regarding how the various systems (monitored by the AHMS) are behaving and is responsible in producing the aircraft flight behaviours. 


\section{A. Aims of the AHMS}

As indicated in Section [C] the AHMS aims to:

1. Health Monitor: to constantly monitor the conditions of the aircraft (itself) and its external environment conditions, and uses both the sensory and actuators values in order to produce an overall measure of health for the aircraft.

2. Fault Tolerance: to ensure that the desirable and safe flight behaviours are provided at all times by executing flight behaviours according to the health value.

The adaptive capabilities of the AHMS are important because the AHMS is able to adapt its functionalities according to its current safe conditions. This helps ensure that any erroneous behaviours indicated and corrective behaviour made correlates with the current safe conditions of the aircraft. This capability is where the traditional fault tolerance flight controller fall short off.

\section{B. Fault tolerance flight controller}

Traditionally fault tolerance flight controller (FTFC) can be achieved through:

1. Hardware redundancy, where identical sensors are used to measure the same parameter/system, and with a voting scheme helps to identify for any errors.2] For example, in a system with three redundant sensors, if one of the redundant signals differs significantly from the other two, the differing signal is eliminated.

2. Analytical redundancy, achieved by creating a mathematical model of the system that would otherwise be generated by a redundant hardware. It consists of two main processes: (i) residual generation and (ii) residual evaluation. ${ }^{\sqrt[3]{4}}$ In its simplest form, the difference between the model estimate and sensor measurement is used to generate an error residual. This residual is then monitored to detect and identify faults.

Hardware redundancy clearly has serious cost, power and weight implications. Due to these implications, analytical redundancy is a more appealing approach for fault tolerant control systems. The AHMS falls within the category of analytical redundancy.

The most common technique used for analytical redundancy is through the use of Kalman filtering techniques,$\sqrt[5]{5}$ whereby a bank of $n$ observations models is generated off-line and stored in the flight computer. Out of these models, $n-1$ are theorised models of different types of sensor failure modes, while the remaining one represents nominal system of the aircraft. Sensor failure detection is achieved by monitoring Bayesian probabilities generated for each of the $n-1$ failure mode observation matrices. 2 One drawback to this technique is, it is limited to the region of linear dynamics since it is based on the working assumption of Kalman filters. Another drawback is that this method relies on predetermined failure models for failure detection. If the output of a damaged system does not agree with any of the $n$ failure models, no failure is detected and identified.

Other techniques proposed to overcome the drawback of linear dynamics are the use of Artificial Neural Network,$\sqrt[6,7]{7}$ and Neuro-Fuzzy FTFC 8 , 9 These techniques, similar to Kalman filtering techniques, require prior training/data to inform decision. It also fall short if the damaged system or error does not agree with any of the failure models represented by the algorithms.

\section{FTFC vs AHMS}

The AHMS aims to preform its functionalities without a prior understanding of error (thus, without the need of failure models). AHMS detects error when there is a deviation from safe or normal system behaviour. AHMS learns of safe behaviours whilst the aircraft is in flight, by monitoring and summarising the aircraft's sensors and actuators values in order to produce an overall measure of health for the aircraft.

Furthermore, the FTFC techniques concentrates on the detection, identification and accommodation (DIA) of physical (hard) errors found within the aircraft. The AHMS also aims to perform similar capabilities; but what significantly differs the AHMS to the FTFC is, the AHMS also aims to perform the DIA for both the hardware errors as well as the erroneous flight behaviours (soft errors) caused by the hardware faults and erroneous flight controls produced by the flight controller. 
To have the ability to detect soft errors is important because a number of aircraft disasters were because of such errors. These errors were found predominantly when the aircraft is flying in bad weather conditions. 10 -13 Such capabilities would therefore allow for safer flight outcome despite flying in whatever the conditions.

\section{The development of the AHMS}

The aims of the AHMS are similar to adaptive capabilities and functionalities performed by the biological immune system. Therefore, the biological immune system (BIS) is used as the inspiration and basis for the development of the AHMS.

\section{Inspiration from biology}

BIS protects the body by performing two main functionalities ${ }^{14}$ :

1. The innate immune system (iIS) is responsible in the detection of invasive pathogenic bodies that can effect the health of the body. The iIS classify if the antigens (and other cells) that were detected by the iIS are useful or harmful (pathogenic antigen) for the body. iIS does so using the information regarding what these antigens do to the body and the information that the body has at birth, that was prescribed in the DNA.

2. The adaptive immune system (aIS) is responsible in providing further adaptive detection capabilities as well as in the elimination of the detected pathogenic bodies. aIS uses information from the iIS to ensure safe immune response are performed. This prevents the aIS from attacking the body's own cells or any useful antigens that are helping to maintain and improve the health of the body. Erroneous immune response can lead to autoimmune diseases.

Adaptation is one of the key characteristics of the BIS. This is because, due to the size of the pathogens (typically they are single-celled organisms), they have very high mutation rates and can evolve to overcome the immune system response. Therefore, BIS must adapt its functionalities and capabilities in order to detect and eliminate the newly (evolved) variance of these organisms.

\section{The AHMS-IIF}

The AHMS therefore uses an immune-inspired framework or IIF to provide for its required functionalities, or the AHMS-IIF. The IIF described in Ref. 15 is used as the basis for the development of the AHMS-IIF. This framework combines the functionalities inspired by how the innate immune system (iIS) and adaptive immune system (aIS) provide for its immune functionalities described in Section II]D[1.

The AHMS-IIF framework consists of three parts:

1. Innate: responsible in performing the (innate) error detection capabilities similarly to the iIS. Innate performs innate error detection by monitoring the behaviour of specific and critical components of the aircraft, ensuring that the monitored system is performing within its normal operating conditions. Further description on Innate is described in Section III|B|1. Innate is based on the technique presented by Ref. 16 and Ref. 17 .

2. Adaptive: responsible in performing the more adaptive error detection capabilities similarly to the aIS, as well as providing a health value for the monitored system. Similar to biology, Adaptive calculates the health value for the aircraft using the information produced by Innate, and associate this value to that of the sensors and actuators values (not monitored by Innate) that can describe the flight behaviour and characteristic of the aircraft at that time. Adaptive provides a prognosis of the change in the health value for the aircraft, when similar behaviour is performed. Large changes to the health value indicate that there maybe fault and/or erroneous behaviour performed by the flight controller of the aircraft, with Innate helps identifying the causes to the detected erroneous behaviour. Further description on Adaptive is described in Section III/B]2, Adaptive is based on the adaptive B-cell immune-inspired algorithm presented in Ref. 18 .

3. Compensation: responsible in performing error compensation to ensure fault tolerance. Error compensation performs its functionalities similarly to the aIS, and uses the error detection information provided by Innate and Adaptive. Further description on Compensation is described in Section III]B]3. 
How these three components interact with each other in order to achieve its objective are described in much detail in Ref. 15. The following section describes how the IIF in Ref. 15 is modified and instantiated in order to achieve the described aims and objectives presented in Section IC.

\section{Integrating the $A H M S-I I F$ with the Aircraft's Flight Controller}

\section{A. X-Plane Flight Simulator}

$\mathrm{X}$-Plane flight simulator is chosen to conduct the experiments. X-Plane flight simulator ${ }^{19}$ is a comprehensive and powerful flight simulator that can produce the flight dynamics that allows the users the ability to predict the flight characteristics for all types of aircrafts. The X-Plane scenery and environmental simulations also almost realistically model varying weather conditions and describes how these weather conditions affect flight behaviour. X-Plane also includes detailed failure modelling when introduced to the aircraft instruments, engines, flight controls, or any other systems of the aircraft that is modelled and simulated in X-Plane. The $\mathrm{X}$-Plane Pro version is also a FAA certified flight simulator.

\section{B. Interfacing the $A H M S-I I F$ with the flight controller}

Figure 1 illustrates how the AHMS-IIF interface with the X-Plane Flight Controller. This method of interfacing is chosen because we do not require and are not allowed to make changes to the flight controller (autopilot system).

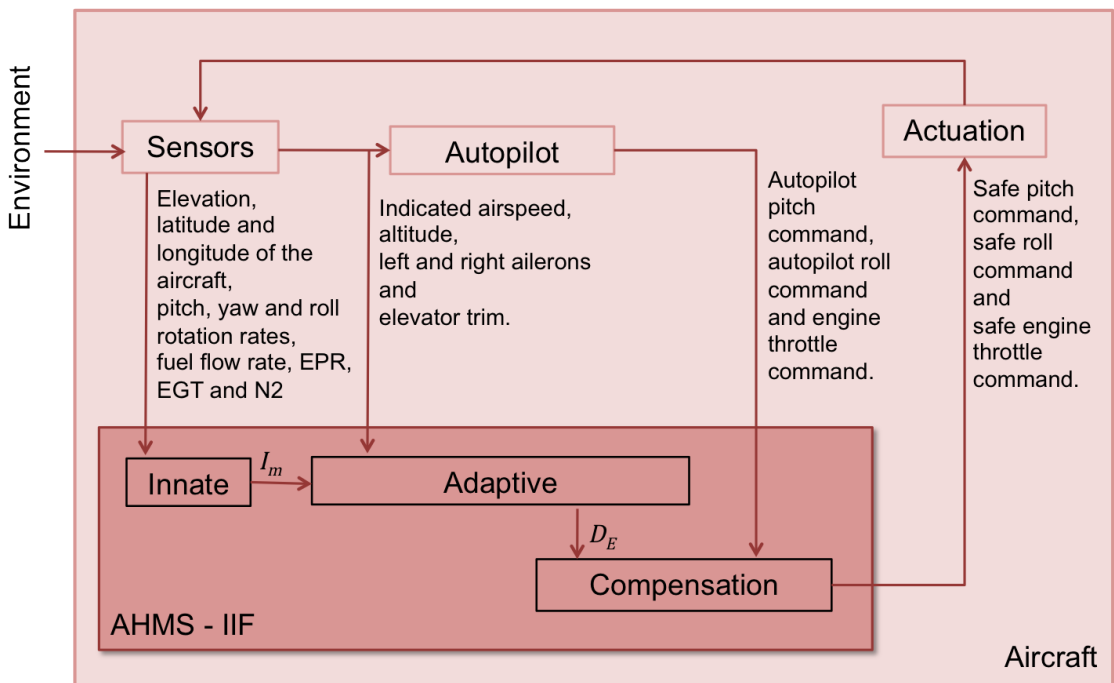

Figure 1. Integrating the AHMS-IIF with the autopilot to help improve the flight behaviour and endurance for the (simulated) aircraft. This method of interfacing is chosen because we do not require (and allowed) to make changes to how the autopilot flies the aircraft. $H_{M}$ is calculated using Eq. (19) and $D_{E}$ is with Eq. (21) presented in Section IIIB 2

How the three parts of the AHMS-IIF provide for these described functionalities are as follows:

\section{Innate}

Innate performs innate error detection by monitoring the behaviour of specific and critical components of the aircraft.

Innate is based on the dendritic cell based algorithm originally presented in Ref. 15 and Ref. 16, aims to monitor the system's behaviour and indicates any deviation from the specified operational boundaries ${ }^{20}$ These operational boundaries can be pre-defined using the information produced from the datasheets or operational manuals of the components and modules used within the system.

As described in Ref. 15, if a component $m$ is monitored by Innate, Innate will produce the signal $I_{m}=$ $\{0, \ldots, 1\}$, calculated based on the progression of the data produced by $m\left(k_{m}\right)$ over time. $I_{m}$ is the normalised 
collective indication that the weighted sum of the three signals $j_{m}^{1}, j_{m}^{2}$ and $j_{m}^{3}$ associated with $k_{m}$ is $\leq 0$ (Eq. (2)) and is within a certain time window $\tau_{m}$ (Eq. (1)).

$$
\begin{gathered}
I_{m}(t)=\frac{\sum_{b=t-\tau_{m}}^{t} k_{m}(b)}{\tau_{m}+1} \\
k_{m}=\left\{\begin{array}{cc}
1 & \text { if } \quad\left(\frac{\sum_{e=1}^{3} w_{e} j_{m}^{e}}{\sum_{e}^{3} w_{e}}\right) \leq 0 \\
0 & \text { otherwise }
\end{array}\right.
\end{gathered}
$$

Innate is used to monitor the power module by monitoring the aircraft's (average) engine characteristics $\left(I_{g}\right)$, and its fuel flow rate $\left(I_{p}\right)$, and the actuation module by monitoring how the aircraft behaves over time and the affect of the flight controller's command $\left(I_{a}\right.$ and $\left.I_{c}\right)$.

- Power module - Fuel flow rate: Substituting $m$ with $p$ in Eqs. (1) and (2), $I_{m}=I_{p}$. Its three signals are (similar to the $I_{p}$ presented in Ref. 15):

$$
\begin{gathered}
j_{p}^{1}=\left\{\begin{array}{cc}
1 & i f \quad\left(10^{2} \frac{F_{T}(t)}{F_{T}(0)}\right)<\frac{F_{T}(0)}{\sum_{d=0}^{t} F_{R}(d)} \\
0 & \text { otherwise }
\end{array}\right. \\
j_{p}^{2}=10^{2}\left|F_{R}(t)-F_{R}(t-1)\right| \\
j_{p}^{2}=\max \left(F_{R}\right)-F_{R}(t)
\end{gathered}
$$

$t=0$ indicates the start of flight. $F_{T}(t)$ is the amount of fuel on-board at time $t . F_{R}(t)$ and $F_{R}(t-1)$ are the total fuel flow rate at time $t$ and $t-1 . \max \left(F_{R}\right)$ is the maximum fuel flow rate allowed for the aircraft. $w_{p}^{1}=w_{p}^{2}=-8$ and $w_{p}^{3}=8 \cdot \tau_{p}=8$.

- Power module - The behaviour of the engine for the aircraft: Substituting $m$ with $g$ in Eqs. (1) and (2), $I_{m}=I_{g}$. Its signals are:

$$
j_{g}^{i}=x_{i} \frac{d x_{i}}{d t}
$$

- Substituting $i$ with 1 in Eq. (6): $x_{1}$ is the engine pressure ratio or EPR at time $t$ for the engine over the maximum EPR value $(\max (E P R))$, average over all engines (Eq. $(7))$.

$$
x_{1}=\frac{\sum_{k=1}^{N_{E}} \frac{E P R_{k}(t)}{\max (E P R)}}{N_{E}}
$$

$N_{E}=$ number of engines in the aircraft.

- Substituting $i$ with 2 in Eq. (6): $x_{2}$ is the engine gauge temperature or EGT at time $t$ over the maximum EGT value for the engine $(\max (E G T))$, average over all engines (Eq. (8)).

$$
x_{2}=\frac{\sum_{k=1}^{N_{E}} \frac{E G T_{k}(t)}{\max (E G T)}}{N_{E}}
$$

$$
6 \text { of } 25
$$


- Substituting $i$ with 3 in Eq. (6): $x_{3}$ is the ratio of the high compressor speed or N2 speed at time $t$ over the maximum $\mathrm{N} 2$ speed value for the engine $(\max (N 2))$, average over all engines $(\mathrm{Eq} .(9))$.

$$
x_{3}=\frac{\sum_{k=1}^{N_{E}} \frac{N 2_{k}(t)}{\max (N 2)}}{N_{E}}
$$

$w_{g}^{1}=w_{g}^{2}=-8$ and $w_{g}^{3}=8 . \tau_{g}=8$.

- Actuation module - How the aircraft moves in the 3-dimensional plane: Substituting $m$ with $a$ in Eqs. (1) and (2), $I_{m}=I_{a}$. The three signal are (based on the equations presented in Ref. 15):

$$
j_{a}^{1}=\left|\frac{E_{L}(t)-E_{L}(t-1)}{\max \left(E_{L}\right)}\right|
$$

$E_{L}(t)$ and $E_{L}(t-1)$ are the elevation of the aircraft at times $t$ and $t-1 . \max \left(E_{L}\right)$ is the maximum (safe) elevation allowed for the aircraft to fly at.

$$
\begin{gathered}
j_{a}^{2}=10^{5}\left(\frac{\sum_{d=1}^{8} \Delta Z(d-1)-\Delta Z(d)}{8}\right) \\
\Delta Z=\sqrt{\left(\Delta X^{2}+\Delta Y^{2}\right)} \\
\Delta X=L_{O}(t)-L_{O}(t-1) \\
\Delta Y=L_{A}(t)-L_{A}(t-1)
\end{gathered}
$$

$L_{O}(t)$ and $L_{A}(t)$ are the longitude and latitude of the aircraft at time $t$. $L_{O}(t-1)$ and $L_{A}(t-1)$ are the longitude and latitude of the aircraft at time $t-1$.

$$
j_{a}^{3}=10^{3} \sqrt{\left(\frac{\sum_{d=0}^{7} \Delta X(d)}{8}\right)^{2}+\left(\frac{\sum_{d=0}^{7} \Delta Y(d)}{8}\right)^{2}}
$$

$w_{a}^{1}=w_{a}^{2}=-8$ and $w_{a}^{3}=8 . \tau_{s}=8$.

- Actuation module - How the aircraft moves on its point axis: Substituting $m$ with $c$ in Eqs. (1) and (2), $I_{m}=I_{c}$. The three signals are:

$$
\begin{aligned}
& j_{c}^{1}=\frac{\left(Q_{R}(t)\right)\left(Q_{R}(t)-Q_{R}(t-1)\right)}{180} \\
& j_{c}^{2}=\frac{\left(R_{R}(t)\right)\left(R_{R}(t)-R_{R}(t-1)\right)}{180} \\
& j_{c}^{3}=\frac{\left(P_{R}(t)\right)\left(P_{R}(t)-P_{R}(t-1)\right)}{180}
\end{aligned}
$$

$Q_{R}(t), R_{R}(t)$ and $P_{R}(t)$ are the pitch, yaw and roll rotation rate (in degree per second or $\mathrm{deg} / \mathrm{sec}$ ) of the aircraft at time $t$; and $Q_{R}(t-1), R_{R}(t-1)$ and $P_{R}(t-1)$ are the pitch, yaw and roll rotation rate at time $t-1 . w_{c}^{1}=w_{c}^{2}=-8$ and $w_{c}^{3}=8 \cdot \tau_{c}=8$. 


\section{Adaptive}

Adaptive (Algorithm 1, initially presented in Ref. 15) is based on the adaptive B-cell immune-inspired algorithm presented in Ref. 18. Adaptive uses (i) the sensors values not monitored by Innate that can described the behaviour and characteristics of the aircraft $(R(t)$ ), as well as (ii) the information from Innate's $I_{p}$ (Eqs. (3) to (5p), $I_{g}$ (Eqs. (6) to (9p), $I_{a}$ (Eqs. (10) to (15)) and $I_{c}$ (Eqs. (16) to (18)), in order to provide for an overall health information for the aircraft (Eqs. (19) and (20)), at the instantiation of the flight controls that resulted in $R(t)$.

$$
\begin{gathered}
H_{M}(t)=\frac{I_{p}(t)+I_{g}(t)+I_{a}(t)+I_{c}(t)}{4} \\
H_{z_{i}}^{D}(t)=\left\{\begin{array}{cc}
\left(H_{z_{i}}^{D}(x)+H_{M}(t)\right) / 2 & \text { if match } \\
H_{M}(t) & \text { otherwise }
\end{array}\right.
\end{gathered}
$$

$H_{z_{i}}^{D}(x)$ is the aircraft's value of health at its previous execution of the same behaviour (at time $x$ ).

Error detection is performed by indicating any change to the health value $H_{z_{i}}^{D}$. Large change to the health value indicate that there maybe faults and/or erroneous behaviours performed by the flight controller of the aircraft.

Adaptive provides for it functionalities by first creating the profile of the aircraft's flight behaviour at its instantiation of the flight control at time $t$ or the $R(t) . R(t)$ is compared against previously flown flight behaviours stored in the aircraft's behavioural profile $P$ (lines 14 to 22 in Algorithm 1). The aircraft's behavioural profile $P$ consists of $q$ is the number of detectors, with each behaviour is stored in a detector $z_{i}$. $i \in q$. If the behaviour is new $\left(R(t) \neq z_{i}\right), R(t)$ is stored in $\mathrm{P}, R(t) \rightarrow z_{q+1}$ (lines 23 to 28 in Algorithm 1).

$R(t)$ consists of the following information:

- the elevation of the aircraft from mean sea level (MSL): provided by the altitude indicator of the aircraft. This is calculated based on the barometric pressure of the outside air.

- the fuel flow rate of the aircraft,

- the speed of aircraft: provided by the indicated airspeed indicators

- the control output of the aircraft: the output to the left and right ailerons and as well as the elevator trim, and

- the health of aircraft at time $t, H_{z_{i}}^{D}(t)$.

$H_{z_{i}}^{D}(t)$ is the health value associated with a particular flight behaviour stored by the detector $z_{i}$ at time $t$, and is calculated using the information provided by Innate (Eq. 20p). A deviation of health is detected when $R(t)=z_{i}$ but $D_{E}>\eta$. $D_{E}$ calculated using Eq. (21). If $R(t) \neq z_{i}, D_{E}=0$.

$$
D_{E}(t)=H_{z_{i}}^{D}(t)-H_{z_{i}}^{D}(x)
$$

A behaviour is considered safe if $D_{E} \leq \mu$.

The combination of Innate and Adaptive allows the AHMS-IIF to achieve its objectives without prior training/optimisation of the algorithm or the need for failure models. This is because the AHMS-IIF builds the understand of safe flight behaviour whilst in-flight and perform error detection based on this information. This is one of the great advantage of $A H M S-I I F$ in comparison to the other techniques presented in Section IIIB

\section{Compensation}

A deviation of health, $D_{E}(t)$ (Eq. (21)), indicates if there is a deviation to the health of the aircraft when it is performing a specific previously executed flight behaviour $\left(R(t)=z_{i}\right)$. A deviation in health indicates that the conditions for which the aircraft is performing that particular behaviour has changed; and this can be detrimental to the aircraft.

If a large deviation is detected $\left(D_{E}>\eta\right.$, illustrated in Figure $\left.2 \mathrm{a}\right)$, the $A H M S-I I F$ will indicate and perform the necessary error compensation. Algorithm 2 indicates the steps used to perform error compensation. 


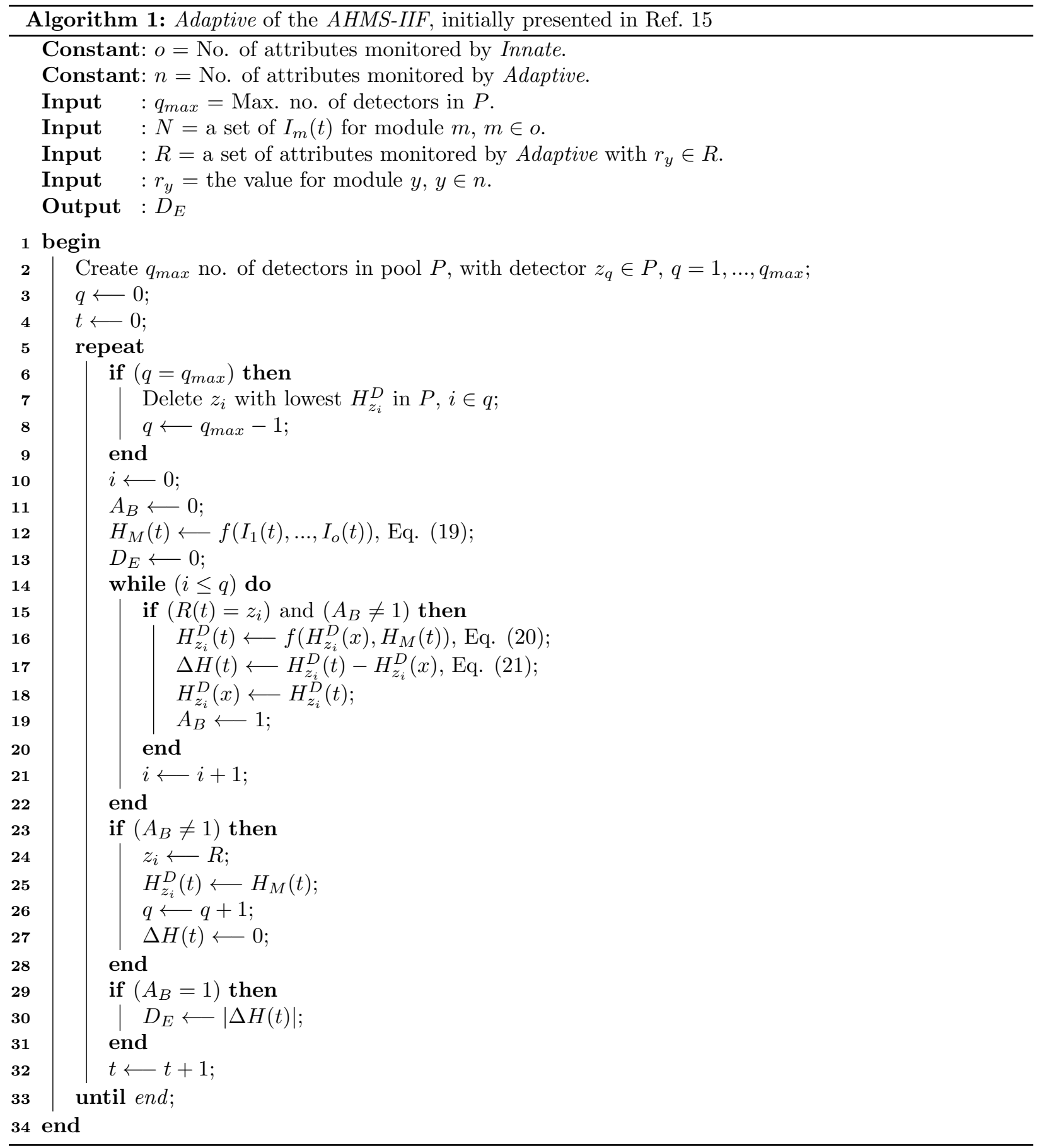




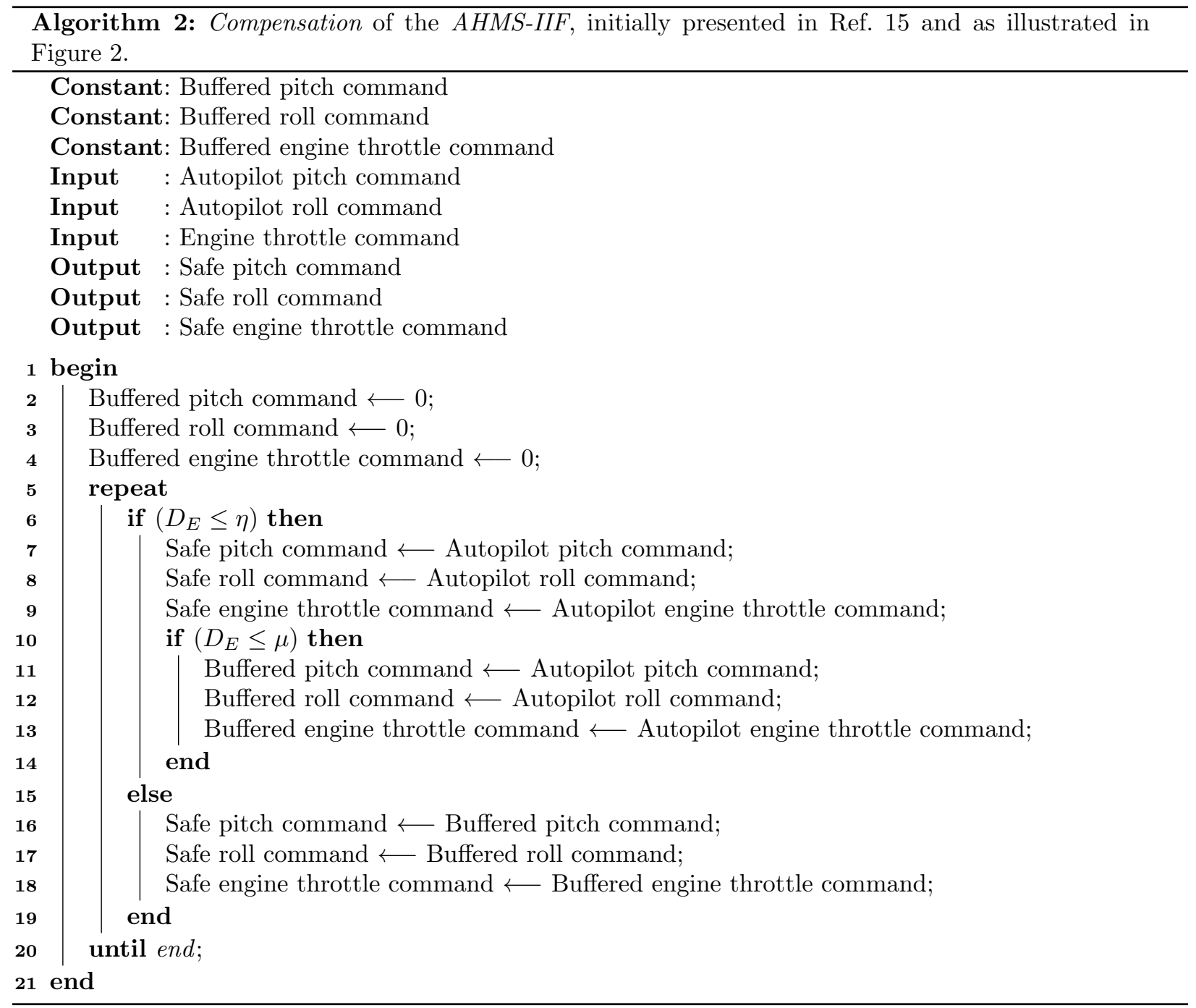




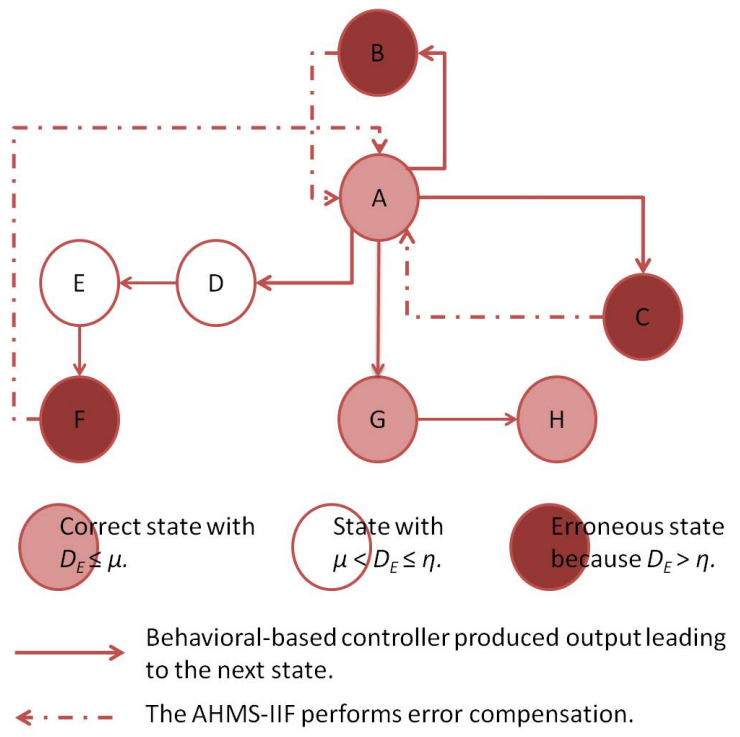

(a) How the AHMS-IIF affects the behavioural changes (state transitions) of the aircraft; starting from state A and ending at state $\mathrm{H}[15$

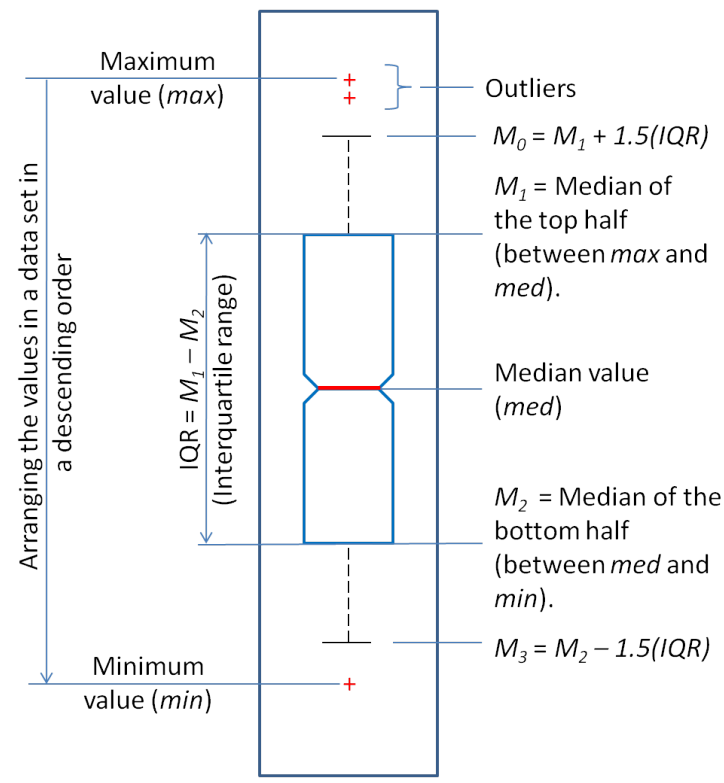

(b) Definition of a box plot. "Safe" flight behaviour $\left(D_{E} \leq \mu\right)$ is when $D_{E}$ lies within the IRQ. Erroneous behaviour $\left(D_{E}>\eta\right)$ is when $D_{E}$ is an outlier $\left(D_{E}<\right.$ $M_{3}$ or $\left.D_{E}>M_{0}\right)$

Figure 2. How Compensation provides for fault tolerance. Compensation ensures safe state transition, in order to help achieve the aims of the AHMS-IIF. An erroneous behaviour is detected when there is a deviation to the health value of aircraft calculated using Eq. (20) and (21).

\section{Characterising health using a box plot}

The values for $\mu$ and $\eta$ (Figure 2a) required for Compensation should be appropriately defined in order to correctly classify what is "safe" and "erroneous" flight behaviours. If erroneous flight behaviours are defined as behaviours with large deviation to its health value $H_{z_{i}}^{D}\left(D_{E}>\eta\right)$, therefore "safe" flight behaviours are assumed to be behaviours with small value of $D_{E}\left(D_{E}<\mu\right)$. When $D_{E}$ is small, this indicates that a behaviour will not deviate from what the aircraft will considered as "normal" system's operations.

Box plot defines the distribution of values for a variable, without making any assumptions of its underlying statistical distribution. Because of this, box plot ${ }^{21}$ was chosen to help us classify "safe" and "erroneous" flight behaviours.

"Safe" behaviour is classified as when $D_{E}$ lies between the lower quartile value $\left(M_{1}\right.$ in Figure 2 $\left.\mathrm{p}\right)$ and the upper quartile value $\left(M_{2}\right.$ in Figure 2b) or the interquartile range (IQR) of the $D_{E}$ distribution. IQR $=M_{1}-M_{2}$. Erroneous behaviour $\left(D_{E}>\eta\right)$ is when $D_{E}$ is an outlier $\left(D_{E}<M_{3}\right.$ or $\left.D_{E}>M_{0}\right)$.

Algorithm 3 describes how to automate the $\mu$ and $\eta$ values. 


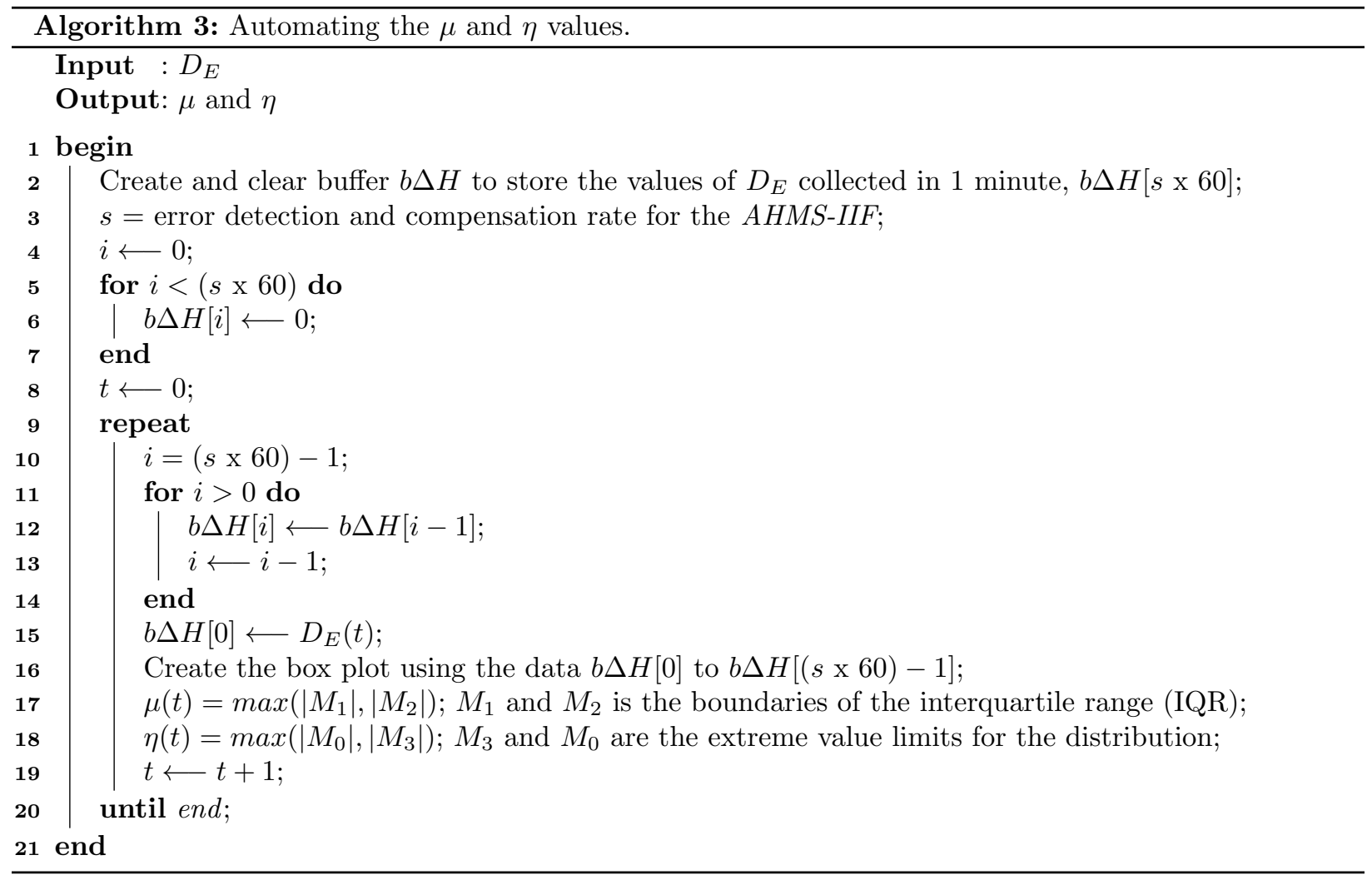

\section{Experiments: The Flight Simulations}

The aircraft used for the flight simulations is the Airbus A330-243 ${ }^{22}$ The aircraft was simulated to take off from Manchester Airport (using X-Plane provided AI flight controller) and to fly en-route to New York JFK Airport using the X-Plane provided Flight Management System. The aircraft took off on 1 January at $10.01 \mathrm{am}$. After take off (altitude $>5,000 \mathrm{ft}$ ), the autopilot of the aircraft provides for the necessary controls to ensure that the aircraft flew at constant altitude of $25,000 \mathrm{ft}$ (initially performing airspeed hold at 330 knots until the aircraft reaches $25,000 \mathrm{ft}$, where the aircraft performs altitude hold); unless the aircraft is affected by ice. The aircraft is carrying $96,000 \mathrm{~kg}$ of fuel at the start of the flight.

Ice accretion or ice build up on critical parts of the aircraft will resulted in erroneous indicated airspeed and altitude, leading to the significant loss in altitude as illustrated in Figure 3 . These conditions were too observed when aircraft flew in condition that promotes ice accretions 11,23

AHMS-IIF is integrated with the provided X-Plane flight controller system, as illustrated in Figure1. The AHMS-IIF will monitor the flight behaviours of the aircraft throughout flight and ensure that the autopilot will produce for the best flight controller outputs for the aircraft, suitable for the (internal) aircraft and (external) weather conditions whilst in flight (situation awareness). AHMS-IIF executes its functionalities at every $0.05 \mathrm{~s}$.

Simulation stops when the aircraft reaches (but not land $d^{b}$ ) at New York JFK airport.

\section{A. Flying in icing conditions}

The aircraft is simulated to fly in icing conditions. The initial weather conditions that were simulated at time of take-off are ${ }^{23}$ :

- Visibility $=12.5$ miles CAVOKC

${ }^{\text {a }}$ The autopilot controls are provided by the X-Plane autopilot flight controller systems

${ }^{\mathrm{b}} \mathrm{We}$ are unable to find the suitable command that will land the aircraft at its destination airport

${ }^{\mathrm{c}} \mathrm{CAVOK}$ or ceiling and visibility OK: clear sky with minimal or no cloud coverage 

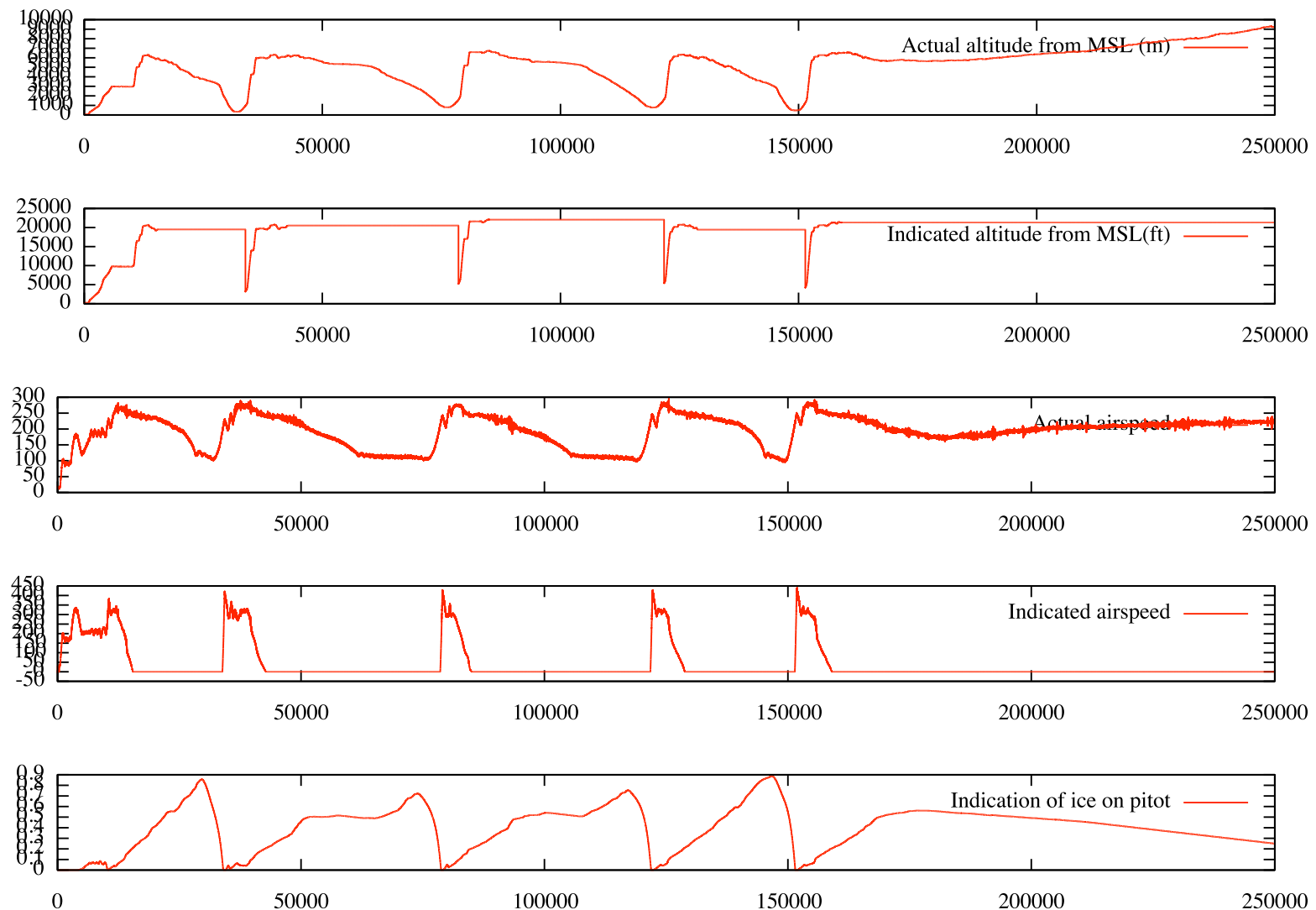

Figure 3. How ice affects the flight of the aircraft. Ice accretion resulted in erroneous indication of airspeed and altitude for the aircraft, by comparing the indicated and actual airspeed and altitude values shown in the figure. These erroneous values have resulted in a number of aircraft crashes.11.23

- Precipitation $=$ Thunderstorms $=$ Wind and turbulence $=$ severe

- Temperature $=0-2^{\circ} \mathrm{C}$

- Barometer pressure at sea level $=29.92$ inch HG

- Upper atmosphere with cumulus overcast, tops at 30,500ft from MSL and bases at 25,500ft from MSL

- Mid atmosphere with cumulus overcast, tops at 22,500ft from MSL and bases at 18,500ft from MSL

- Lower atmosphere with low stratus coverage, tops at 12,500ft from MSL, bases at 8,300ft from MSL

The above conditions remain constant throughout flight.

These weather conditions are simulated because such condition promote ice accretion on the aircraft and can significantly affect the flight behaviour of the aircraft. The results from these simulations provide for a number of erroneous flight behaviours (and conditions) and systems failures that occur whilst in-flight. The AHMS-IIF will therefore aim to indicate for such failures and errors.

Furthermore, to test the capabilities of the AHMS-IIF to increase adaptability and autonomous capabilities for the aircraft, the anti-ice mechanisms was switched off and not in use throughout the flight. This allows us to fully test the capabilities of the AHMS-IIF to adapt the aircraft's flight behaviour to a behaviour suitable for flying in icing conditions with minimal help.

\section{B. Flying in good weather conditions}

The initial weather conditions that were simulated at time of take-off are: 
- Visibility $=25$ miles CAVOK (Celling And Visibility OK)

- Precipitation $=$ Thunderstorms $=$ Wind and turbulence $=$ None

- Temperature $=1.0^{\circ} \mathrm{C}$

- Barometer pressure at sea level $=29.92$ inch HG

- Upper atmosphere has no clouds

- Mid atmosphere has no clouds

- Lower atmosphere has no clouds

The above conditions remain constant throughout flight. When flying in this weather condition, the aircraft will not be affected by ice accretion.

The two weather conditions were chosen because we wish to test the capabilities of AHMS-IIF in detecting erroneous flight behaviour when the aircraft is flying in two very different weather conditions, one almost opposite to the other.

\section{Results of Experiments}

\section{A. Flying in good weather conditions}

Four flights, each, were conducted with and without the instantiation of Compensation of the AHMS-IIF, when flying in good weather conditions. Table 1 shows the characteristics of the eight flights.

Table 1. Comparing with and without the instantiation of the AHMS-IIF, when the aircraft is flying in good weather conditions.

\begin{tabular}{c||c|c|c}
\hline & Remaining fuel at JFK & mean $\left(H_{M}\right)($ std. dev.) & mean(Fuel flow rate) (std. dev.) \\
\hline with Flight A & $41745 \mathrm{~kg}$ & $0.7317(0.1015)$ & $2.5857 \mathrm{~kg}(0.6209)$ \\
\hline with Flight B & $41994 \mathrm{~kg}$ & $0.7431(0.0933)$ & $2.5825 \mathrm{~kg}(0.6299)$ \\
\hline with Flight C & $41970 \mathrm{~kg}$ & $0.7429(0.0937)$ & $2.5839 \mathrm{~kg}(0.6194)$ \\
\hline with Flight D & $40290 \mathrm{~kg}$ & $0.7370(0.0980)$ & $2.6894 \mathrm{~kg}(0.6207)$ \\
\hline \hline without Flight A & $43230 \mathrm{~kg}$ & $0.7439(0.0746)$ & $2.5613 \mathrm{~kg}(0.6324)$ \\
\hline without Flight B & $40950 \mathrm{~kg}$ & $0.7403(0.0748)$ & $2.6508 \mathrm{~kg}(0.6204)$ \\
\hline without Flight C & $42780 \mathrm{~kg}$ & $0.7428(0.0763)$ & $2.5657 \mathrm{~kg}(0.6170)$ \\
\hline without Flight D & $42750 \mathrm{~kg}$ & $0.7433(0.0756)$ & $2.5666 \mathrm{~kg}(0.6271)$ \\
\hline \hline
\end{tabular}

Table 1 shows that there are large variability between the four different flights when they are flown without Compensation of AHMS-IIF, in comparison to flights with Compensation. This shows that with AHMS-IIF, similar flight characteristics between the four different flights can be observed.

This capability can be used to help in the further diagnostic of error to the aircraft; whereby, if an aircraft flown with $A H M S-I I F$ and its health values begin to delineate from normal (therefore flying with dissimilar characteristics to the other flights with $A H M S-I I F)$, there maybe an error to the aircraft. Innate of the AHMS-IIF can points to such error. For example, one of the with Flight D's engine has loss its ability to provide the correct thrust in mid flight. Although no error was indicated at the aircraft's cockpit, but there are differences between the aircraft's engines' EPR, EGT and N2 speed values between the four flights, shown in Figures 45 . The AHMS-IIF has indicated for such error, and aims to provide the necessary compensation to the error. This is as shown in Figures 6.7 .

$A H M S$-IIF helps reduce variabilities between of flights and provides indication to error if variabilities are found. 


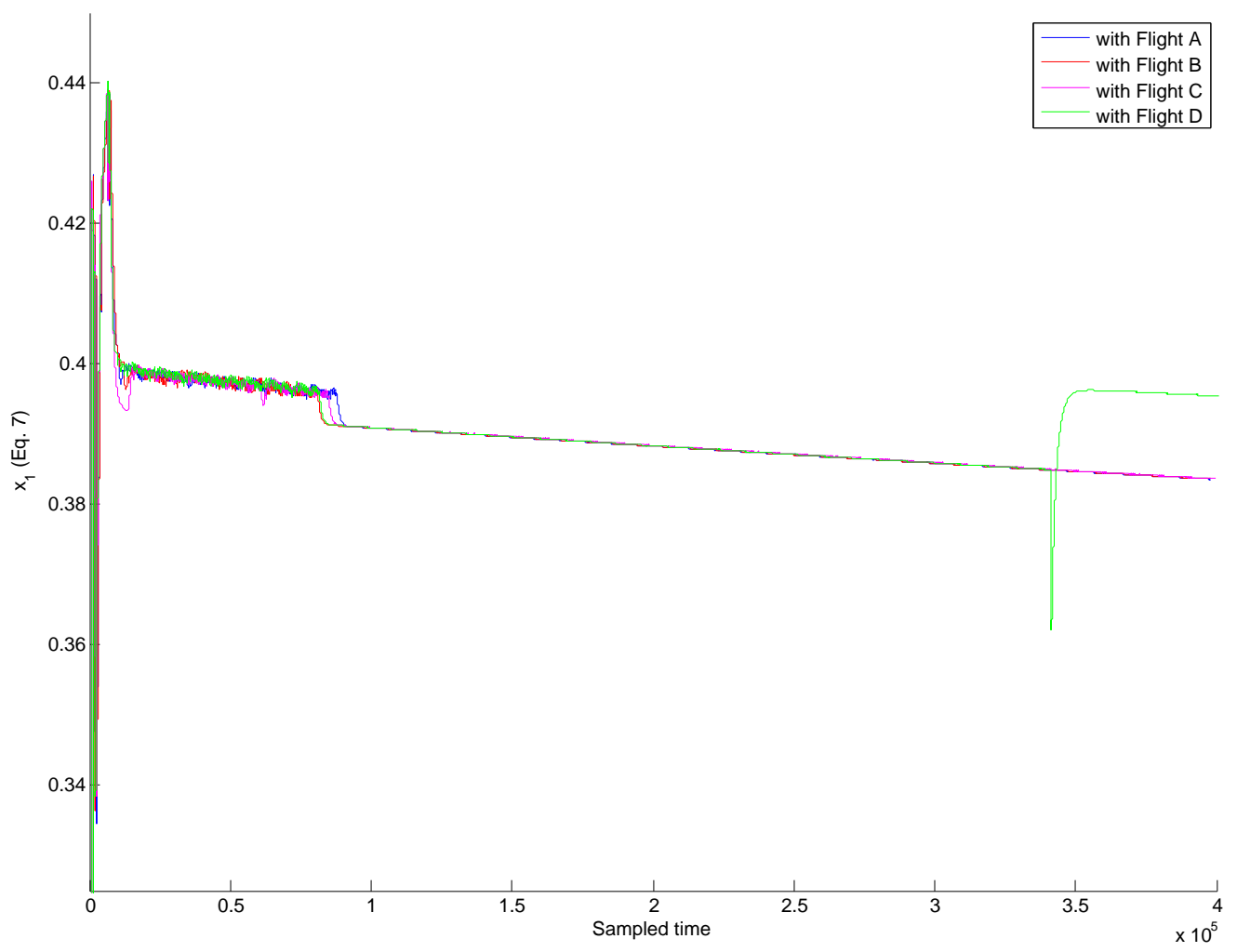

Figure 4. Comparing the $x_{1}$ values for the flights flown with $A H M S-I I F$ with good weather condition. $x_{1}$ is the ratio of the engine pressure ratio or $E P R$ at time $t$ over the maximum EPR value $(\max (E P R))$ for an engine, average over all engines (Eq. (7)). For with Flight D, one of the aircraft's engine has loss its ability to provide the correct thrust in mid flight. 


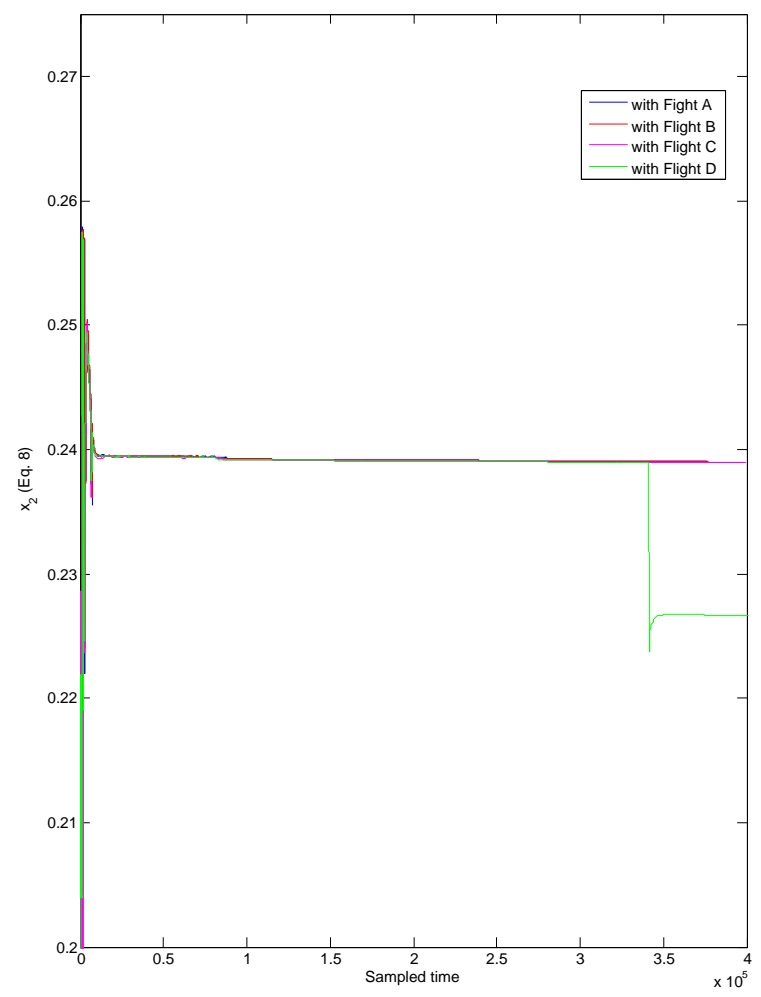

(a) $x_{2}$

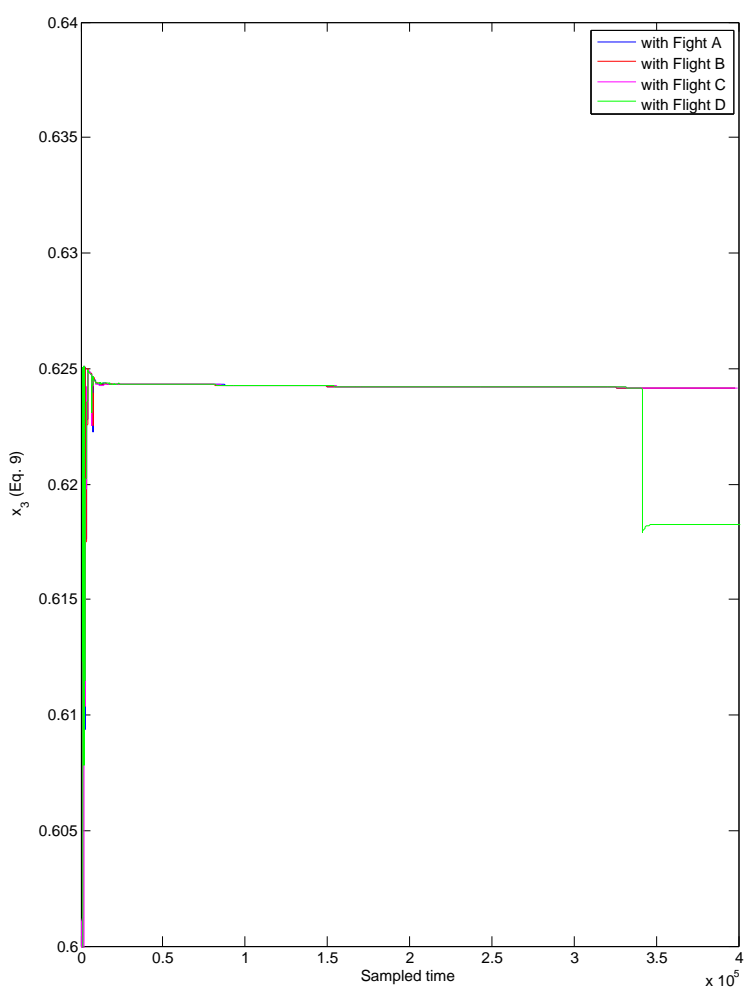

(b) $x_{3}$

Figure 5. Comparing the $x_{2}$ and $x_{3}$ values for the flights flown with $A H M S-I I F$ with good weather condition. $x_{2}$ is the engine gauge temperature or EGT at time $t$ over the maximum EGT value for the engine $(\max (E G T))$, average over all engines (Eq. (8)). $x_{3}$ is the N2 speed at time $t$ over the maximum N2 speed value for the engine $(\max (N 2))$, average over all engines (Eq. $(9)$ ). For with Flight D, one of the aircraft's engine has loss its ability to provide the correct thrust in mid flight. 


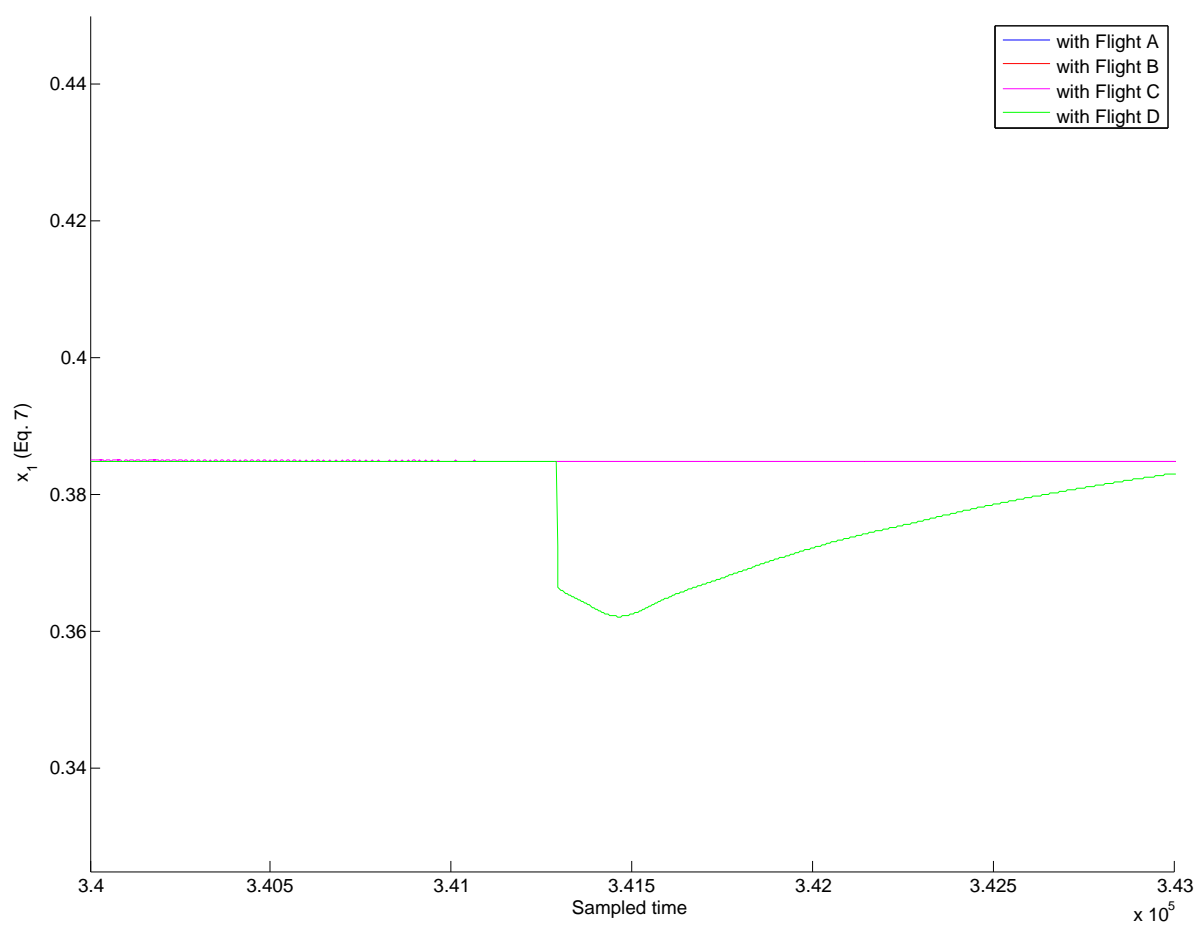

(a) Zooming into Figure 4 at the time of error.

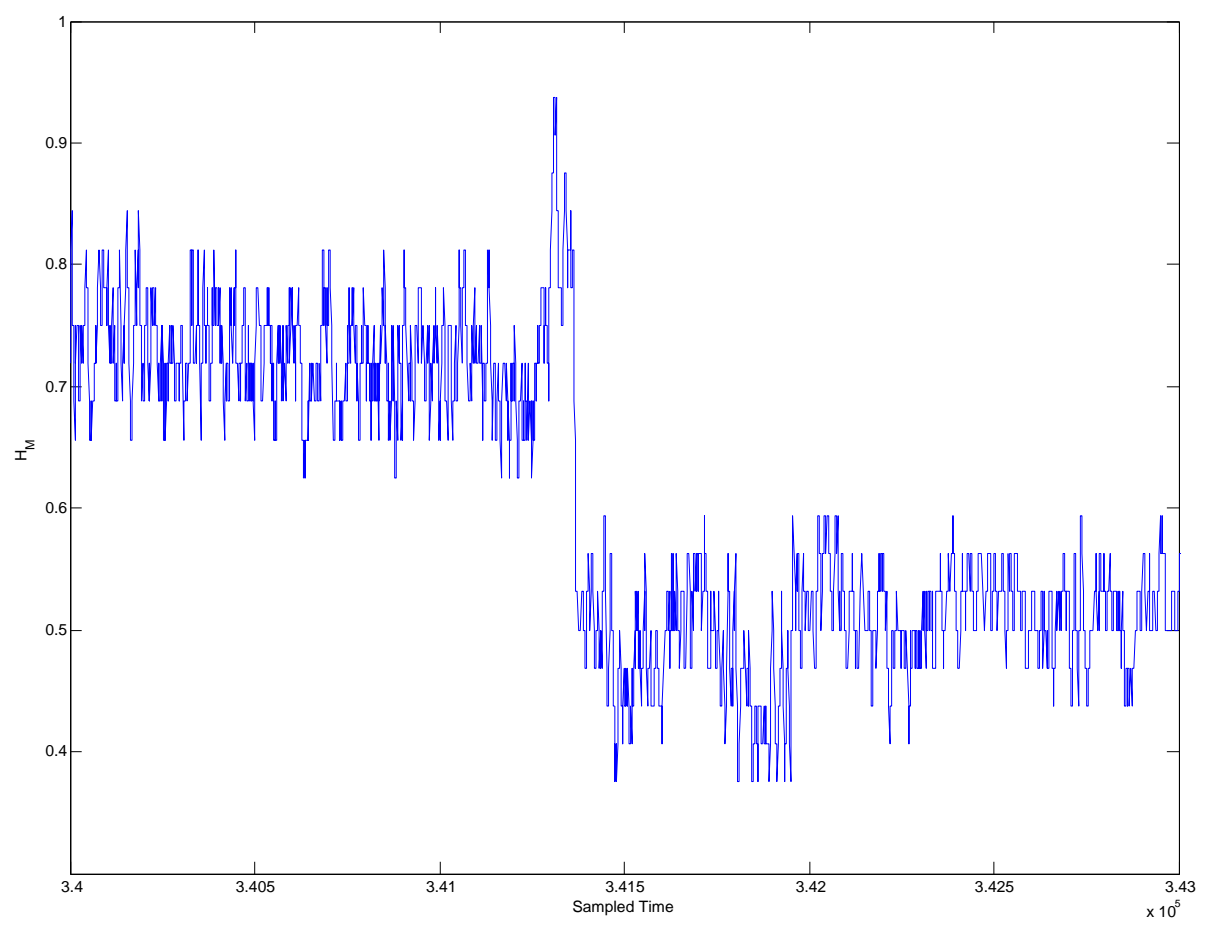

(b) $H_{M}$ at the time of error.

Figure 6. The AHMS-IIF for with Flight D, when one of the aircraft's engine has loss its ability to provide the correct thrust in mid flight. 


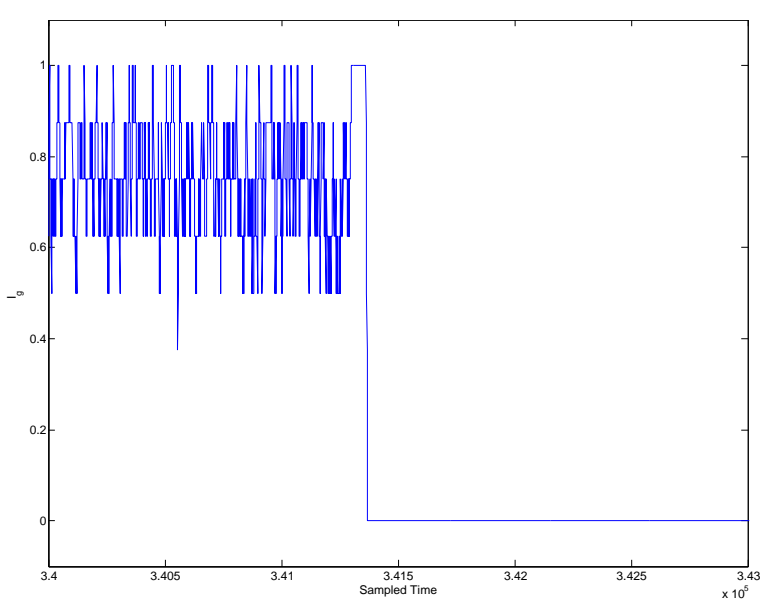

(a) The values of $I_{g}$ (Eqs. 6 to 9 ) at the time of error

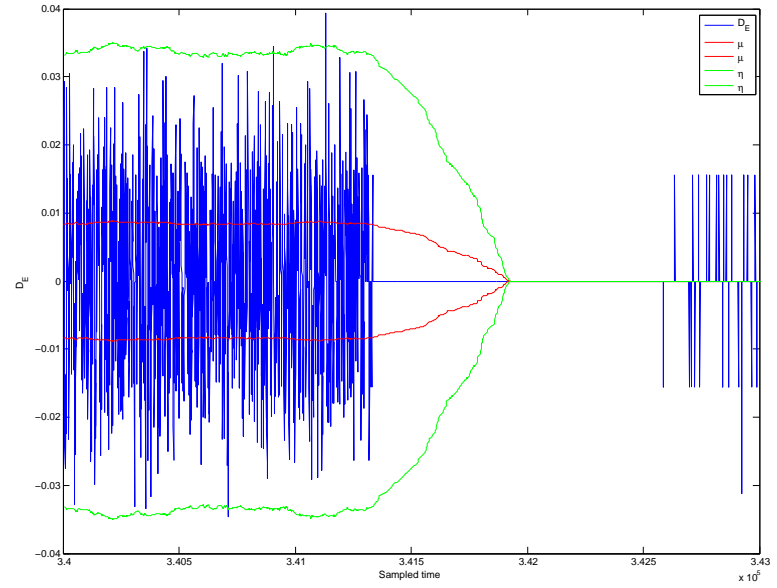

(b) The $A H M S-I I F$ indicating the error, whereby $D_{E}>$ $\eta$ (green lines) prior to and during the error. $D_{E}=0$ at the start of the error because the AHMS-IIF allows for the aircraft's autopilot system to change the control trajectories that can compensate for the error.

Figure 7. The variable of the $A H M S-I I F$ for with Flight D, when one of the aircraft's engine has loss its ability to provide the correct thrust in mid flight.

\section{B. Flying in icing conditions}

Three flights each were simulated with and without the instantiation of the AHMS-IIF.

To test the capabilities of the AHMS-IIF in achieving its objectives, the following comparisons are made between the flights with and without the instantiation of the AHMS-IIF:

1. The significant lost in altitude and airspeed during flight, as illustrated in Figure 3.

2. The ability to reach its destination and the amount of fuel that remains when reaching its destination.

3. The movements made by the aircraft, measured by its pitch roll and yaw rotation rates.

Table 2 provides the comparison results for points 1 and 2; while Figures 8 to 10 for point 3 .

Table 2. Comparing With and Without the Instantiation of the AHMS-IIF

\begin{tabular}{c||c|c|c}
\hline & Affected by Ice? & Arrive at destination? & Remaining fuel at JFK \\
\hline with AHMS Flight 1 & No & Yes & about $2565 \mathrm{~kg}$ \\
\hline with AHMS Flight 2 & No & Yes & about $2565 \mathrm{~kg}$ \\
\hline with AHMS Flight 3 & No & Yes & about $2565 \mathrm{~kg}$ \\
\hline \hline without AHMS Flight 1 & No & Yes & about $1557 \mathrm{~kg}$ \\
\hline without AHMS Flight 2 & Yes & Yes & about $1557 \mathrm{~kg}$ \\
\hline without AHMS Flight 3 & No & Yes & about $1875 \mathrm{~kg}$ \\
\hline \hline
\end{tabular}

Results shows that with the $A H M S-I I F$, the aircraft is able:

1. to stay in-flight longer and further (due to more fuel remaining when flying above JFK airport, as shown in Table 2), and

2. with better flight characteristics and behaviours, when comparing flights with and without the instantiation of the $A H M S-I I F$, as shown in Figures 8 to 10, which show smaller variance to its pitch, roll and yaw rotation rates throughout the flight, indicated by: 


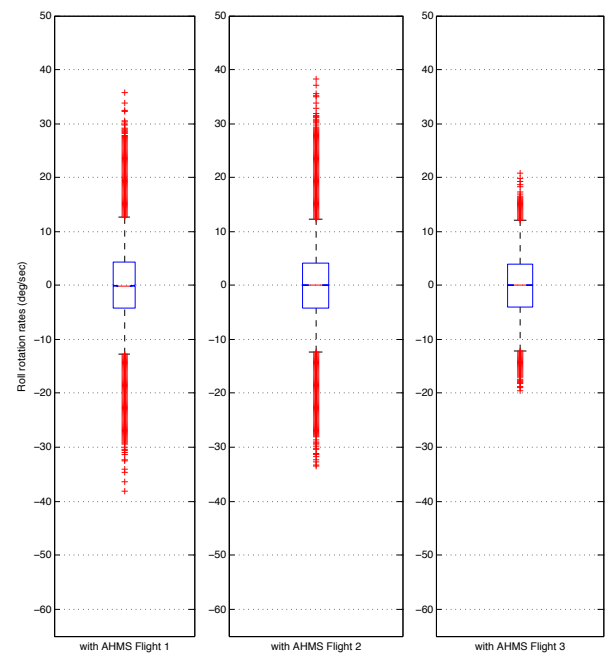

(a) Flying with $A H M S-I I F$
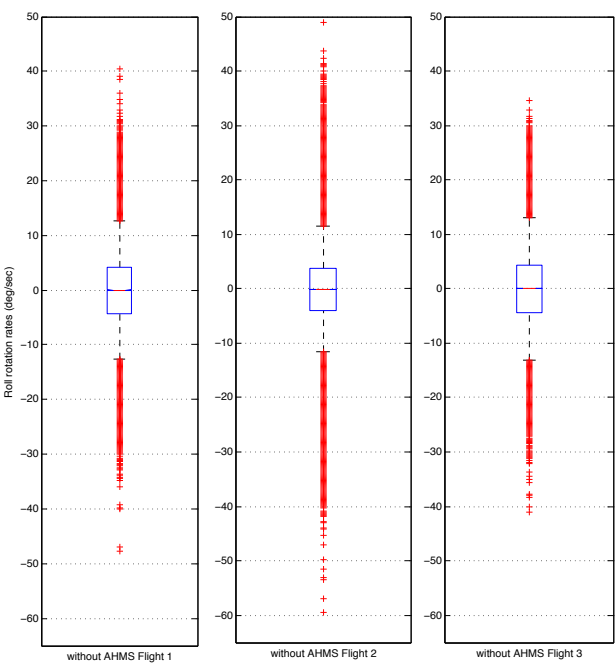

(b) Flying without $A H M S-I I F$

Figure 8. The box plots illustrating the distribution of the roll rotation rates (in $\mathrm{deg} / \mathrm{sec}$ ) for the aircraft, with and without the instantiation of the $A H M S-I I F$. with Flight 1, 2 and 3 have mean values of -0.0188, -0.0025 and $\mathbf{- 0 . 0 0 7 4}$ with standard deviation of $7.3685,7.4925$ and 5.2507 . without Flight 1,2 and 3 have mean values of $\mathbf{- 0 . 0 1 5 6 , - 0 . 0 6 1 9}$ and 0.0011 with standard deviation of $7.4705,7.2758$ and 7.4879 . There are smaller variance to the distribution of the roll rotation rates when the aircraft flew with $A H M S-I I F$ then without.
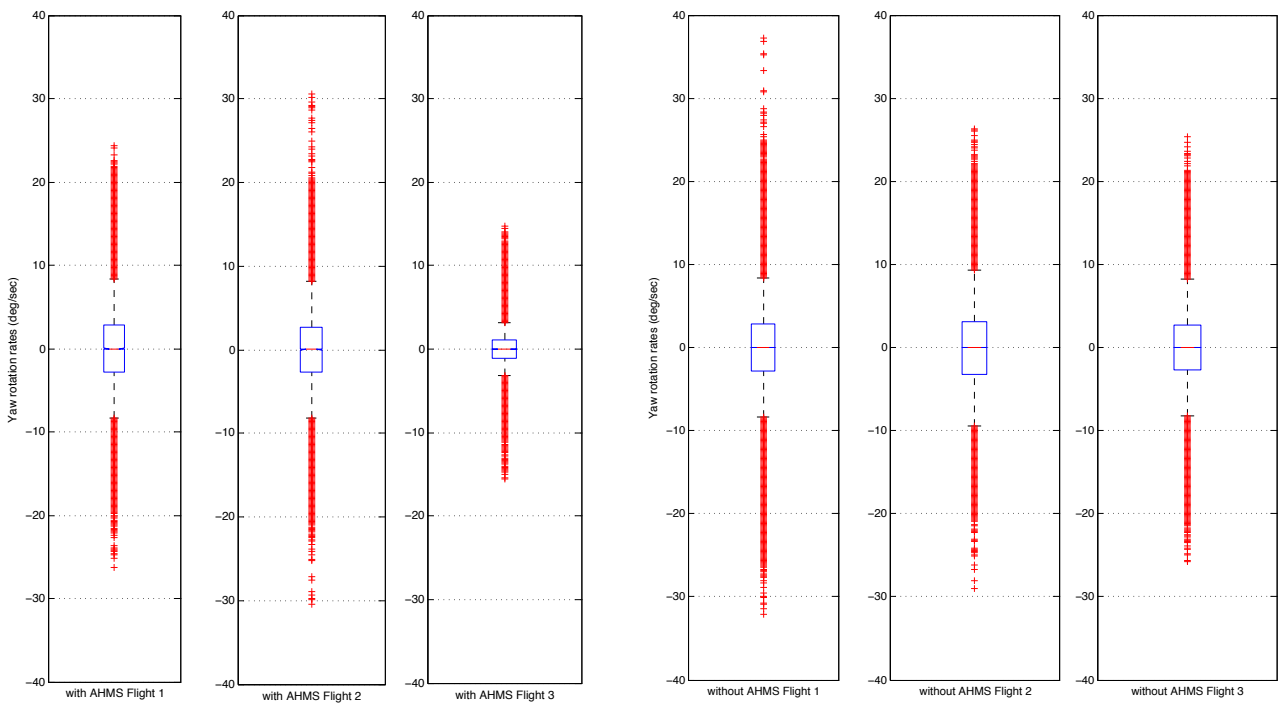

(a) Flying with $A H M S-I I F$

(b) Flying without $A H M S$-IIF

Figure 9. The box plots illustrating the distribution of the yaw rotation rates (in deg/sec) for the aircraft, with and without the instantiation of the AHMS-IIF. with Flight 1, 2 and 3 have mean values of $0.0036,0.0034$ and 0.0040 with standard deviation of $4.5590,4.5310$ and 1.6817. without Flight 1,2 and 3 have mean values of $0.0057,-0.0675$ and -0.0016 with standard deviation of $4.6321,4.9747$ and 4.4827 . There are smaller variance to the distribution of the yaw rotation rates when the aircraft flew with $A H M S$-IIF then without. 

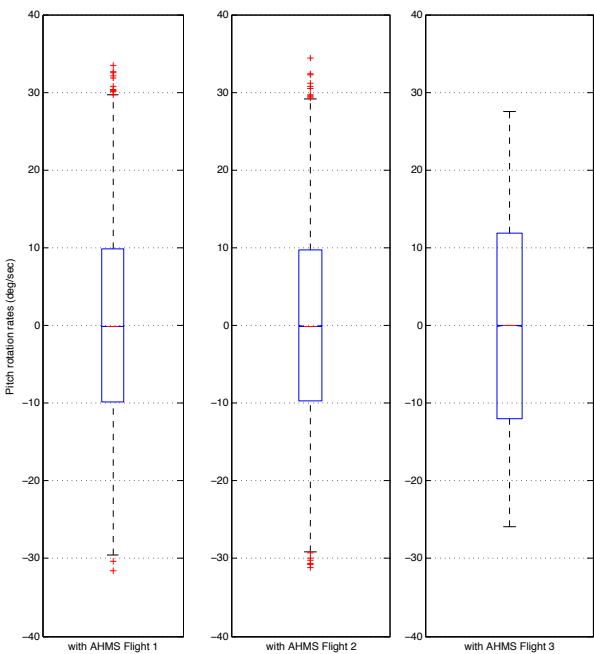

(a) Flying with $A H M S-I I F$
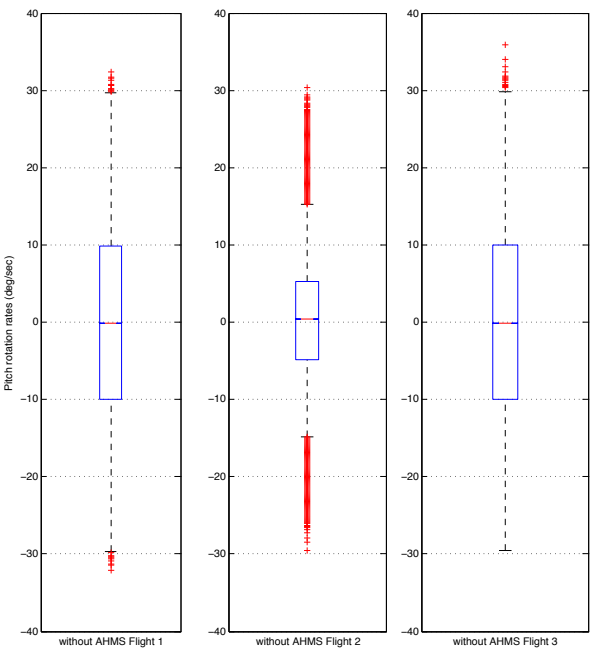

(b) Flying without $A H M S-I I F$

Figure 10. The box plots illustrating the distribution of the pitch rotation rates (in deg/sec) for the aircraft, with and without the instantiation of the $A H M S-I I F$. with Flight 1,2 and 3 have mean values of $0.0339,0.0310$ and 0.0140 with standard deviation of $11.0932,11.0562$ and 12.3073 . without Flight 1,2 and 3 have mean values of $0.0211,0.2772$ and 0.0432 with standard deviation of $11.1746,8.0902$ and 11.2177. There are smaller variance to the distribution of the pitch rotation rates when the aircraft flew with $A H M S$-IIF then without.

(a) the smaller min to max range of the box plots

(b) the smaller mean and standard deviation values

This indicates the capability of $A H M S-I I F$ in providing better situation awareness for the aircraft, which has help provide for better flight characteristics and increase the endurance of the aircraft.

\section{Flying with ice accretion in icing conditions}

The experiments presented show that the aircraft were not significantly affected by ice (Table 2), with or without the instantiation of the AHMS-IIF. The settings were therefore modified to force the aircraft to be affected by ice. This is to fully test the capabilities of the AHMS-IIF to provide for better flight characteristics and to increase the endurance of the aircraft when flying in severe weather conditions. This is achieved by first forcing the aircraft to perform an altitude hold at 9,740ft with airspeed of 330 knots for about 15 minutes (in all experiments the aircraft was flying between 10,000ft - 15,000ft instead of the indicated altitude), before changing the command that forces the aircraft to climb to $25,000 \mathrm{ft}$ (with airspeed hold of 330 knots) and to perform altitude hold at that altitude.

Similar to the previous experiment, four flights, each, were conducted with and without the instantiation of the AHMS-IIF. Table 3 shows how the aircraft is affected by ice accretion with and without the AHMS-IIF. Results also show that the $A H M S-I I F$ can provide for:

1. Better flight characteristics and behaviours. This is indicated by the smaller variance to its pitch, roll and yaw rotation rates throughout the flight, despite flying with ice accretion (and in icing conditions), as shown in Figures 11- 13 that indicate the roll, pitch and yaw rotation rates of aircraft for each flight, and

2. Less affected by ice accretion due to the lower number of drops in altitude, as listed in Table 3 .

3. Better ability to arrive at its destination, as indicated in Table 3 
Table 3. Comparing with and without the instantiation of the $A H M S-I I F$, when the aircraft is affected by ice accretion.

\begin{tabular}{|c|c|c|}
\hline & Affected by Ice? & Arrive at destination? \\
\hline with Flight A & $\begin{array}{l}\text { Yes. Twice resulted in a significant drop in } \\
\text { altitude to }<1000 \mathrm{~m} \text { or }<5000 \mathrm{ft} \text {. }\end{array}$ & $\begin{array}{l}\text { No. Ran out of fuel near } \\
\text { Iles de Madeleine, Canada }\end{array}$ \\
\hline with Flight B & $\begin{array}{l}\text { Yes. Twice resulted in a significant drop in } \\
\text { altitude to }<1000 \mathrm{~m} \text { or }<5000 \mathrm{ft} \text {. }\end{array}$ & $\begin{array}{l}\text { No. Ran out of fuel near } \\
\text { Apple River, Canada }\end{array}$ \\
\hline with Flight $\mathrm{C}$ & No. & Yes, with $975 \mathrm{~kg}$ of fuel left. \\
\hline with Flight D & No. & Yes, with $10000 \mathrm{~kg}$ of fuel left. \\
\hline $\begin{array}{l}\text { without Flight } \mathrm{A}^{\mathrm{b}} \\
\text { (Figure } 3\end{array}$ & $\begin{array}{l}\text { Yes. Four times resulted in a significant drop in } \\
\text { altitude to }<1000 \mathrm{~m} \text { or }<5000 \mathrm{ft}\end{array}$ & $\begin{array}{l}\text { No. Ran out of fuel near Digby, } \\
\text { Nova Scotia, Canada }\end{array}$ \\
\hline without Flight B & $\begin{array}{l}\text { Yes. Once resulted in a significant drop in } \\
\text { altitude to }<1000 \mathrm{~m} \text { or }<5000 \mathrm{ft}\end{array}$ & $\begin{array}{c}\text { No. Ran out of fuel near } \\
\text { Windham, Connecticut, USA. }\end{array}$ \\
\hline without Flight $\mathrm{C}$ & No. & $\begin{array}{c}\text { No. Ran out of fuel near } \\
\text { Danielson, Connecticut, USA. }\end{array}$ \\
\hline without Flight D & No. & $\begin{array}{c}\text { No. Ran out of fuel near } \\
\text { Eastford, Connecticut, USA. }\end{array}$ \\
\hline
\end{tabular}

a The average fuel flow rate of the aircraft is $2.8677 \mathrm{~kg}, 1.5000 \mathrm{~kg}$ lesser in comparison to others.

$\mathrm{b}$ The aircraft managed to regain altitude of $>25,000 \mathrm{ft}$ after the fourth times being affected by ice. Aircraft reached highest of $44200 \mathrm{ft}$ - the altitude not affected by icing conditions, therefore resulted in longer duration of flight and smaller pitch, yaw and roll rotation rates (Figures 11- 13). The aircraft was not obeying the altitude hold command.

This indicates the capability of $A H M S-I I F$ in providing better situation awareness for the aircraft, by providing for better flight characteristics for the aircraft. Better flight characteristics has help increase the endurance of the aircraft. 


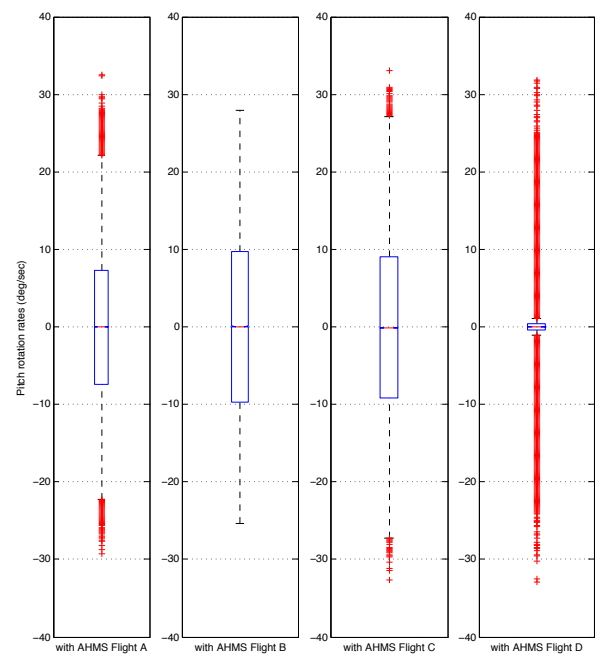

(a) Flying with $A H M S-I I F$

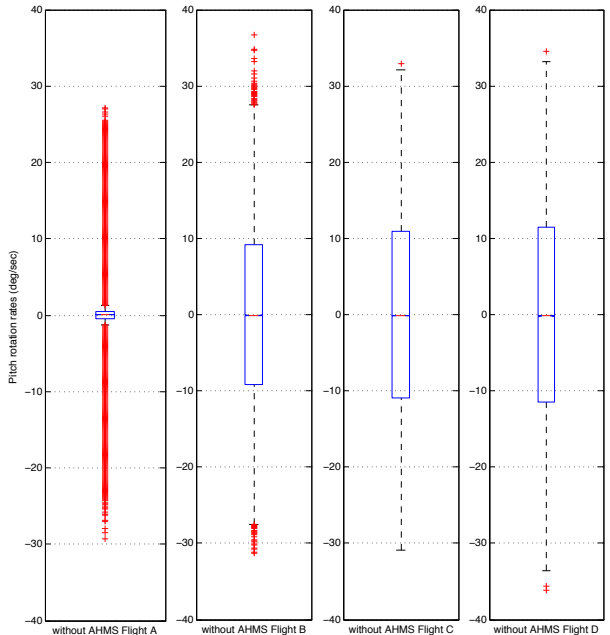

(b) Flying without $A H M S-I I F$

Figure 11. The box plots illustrating the distribution of the pitch rotation rates (in deg/sec) for the aircraft, with and without the instantiation of the AHMS-IIF. with Flight 1, 2, 3 and 4 have mean values of 0.0100 , $0.0133,0.0175$ and 0.0257 with standard deviation of $9.6340,5.9303,10.7345$ and 4.5327 . without Flight 1,2 , 3 and 4 have mean values of $0.0196,0.0456,0.0076$ and 0.0129 with standard deviation of 11.3689, 10.7845, 11.8546 and 12.2928. There are smaller variance to the distribution of the pitch rotation rates when the aircraft flew with $A H M S-I I F$ then without.

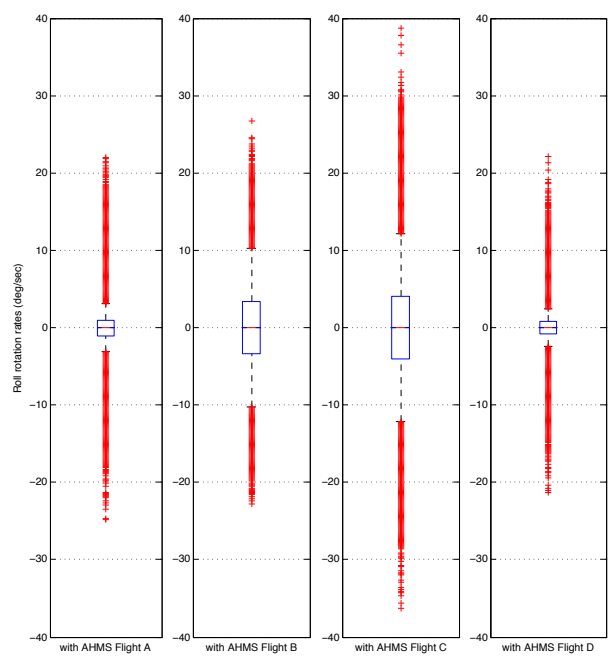

(a) Flying with $A H M S-I I F$

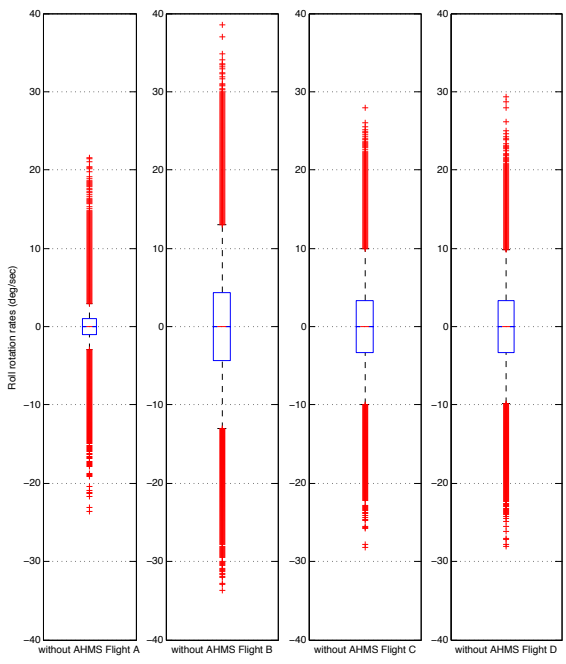

(b) Flying without $A H M S-I I F$

Figure 12. The box plots illustrating the distribution of the roll rotation rates (in deg/sec) for the aircraft, with and without the instantiation of the $A H M S-I I F$. with Flight 1, 2, 3 and 4 have mean values of $-3.0563 \mathrm{x}$ $10^{-4}, \mathbf{0 . 0 0 1 1}, \mathbf{- 0 . 0 0 5 6}$ and $\mathbf{0 . 0 0 1 3}$ with standard deviation of $3.1903, \mathbf{5 . 1 7 9 5}, \mathbf{2 . 9 4 2 5}$ and 2.0172. without Flight $1,2,3$ and 4 have mean values of $-6.8192 \times 10^{-4}, 5.6179 \times 10^{-4}, 0.0035$ and 0.0073 with standard deviation of 2.9425, 7.5934, 5.8819 and 5.3775. There are smaller variance to the distribution of the roll rotation rates when the aircraft flew with $A H M S-I I F$ then without. 


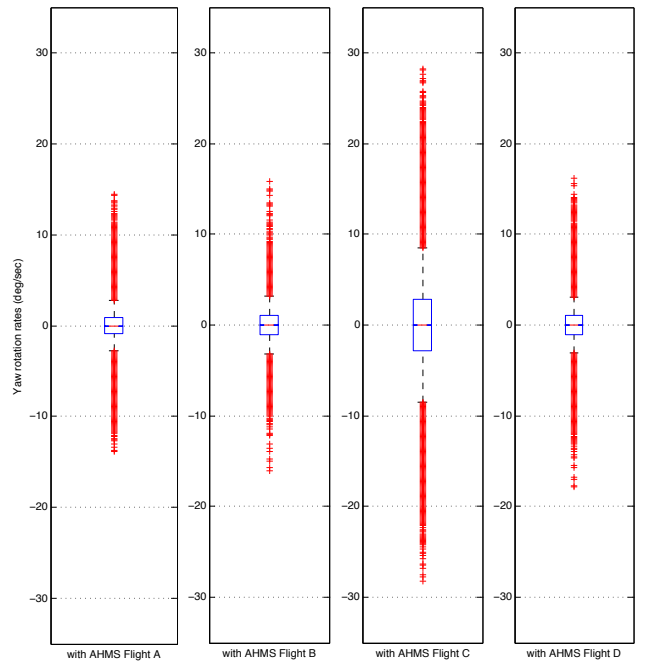

(a) Flying with $A H M S-I I F$

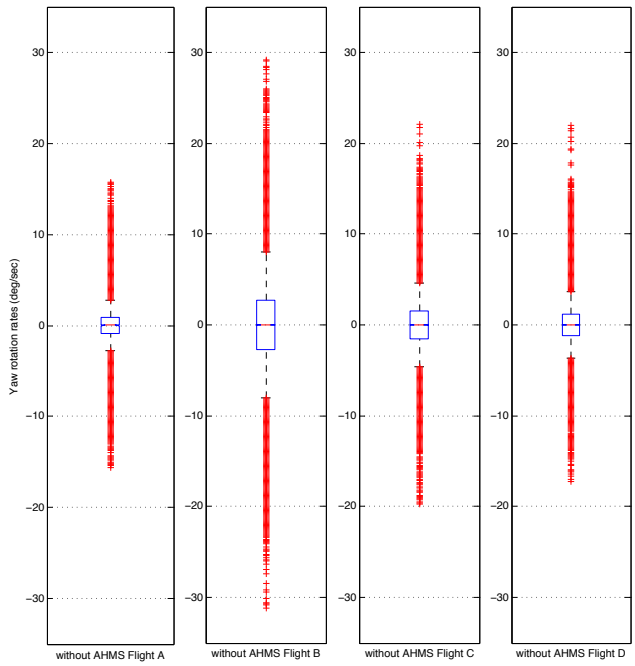

(b) Flying without $A H M S-I I F$

Figure 13. The box plots illustrating the distribution of the yaw rotation rates (in deg/sec) for the aircraft, with and without the instantiation of the $A H M S-I I F$. with Flight 1, 2, 3 and 4 have mean values of 0.0010 , $-0.0155,0.0011$ and 0.0036 with standard deviation of 1.5936, 1.6570, 4.6831 and 1.8194. without Flight $1,2,3$ and 4 have mean values of $0.0015,0.0023,0.0057$ and $5.7287 \times 10^{-4}$ with standard deviation of $1.6891,4.4936$, 2.5825 and 2.1328. There are smaller variance to the distribution of the yaw rotation rates when the aircraft flew with $A H M S-I I F$ then without. 


\section{Conclusion}

Results show that the $A H M S-I I F$ is able to provide for better situation awareness for the aircraft, whereby the aircraft flew with better health that was resulted from better flight characteristics, for example, smaller variance in the movements, pitch, yaw, and roll of the aircraft. These capabilities are useful for unmanned aircraft. This is because the controller, be it the autonomous flight controller or the remote operator, will have additional and useful health information regarding how the current external environmental conditions and/or the internal (mechanical) conditions of the aircraft that can affect its flight behaviours. The AHMSIIF also has the ability to adapt the aircraft's flight behaviours based on this health information.

The AHMS-IIF consists of three parts: (i) Adaptive, (ii) Innate and (iii) Compesnation. Adaptive acts as a Health Monitor that monitors the aircraft flight behaviours and indicates when the aircraft is performing erroneous flight behaviours through the prognosis of the change in the health value for the aircraft using the information produced by Innate. Because of this, Innate can help point out to the causes for the error. Compensation indicates how to accommodate for the detected error.

The AHMS-IIF therefore helps provide for good situation awareness for the aircraft. Good situation awareness helps increase the duration and endurance of flights by manipulating the behaviours of the aircraft according to its internal (mechanical) and external (environmental) conditions. This assists the aircraft to fly better and safer, especially when flying in bad weather conditions, for example in icing conditions that can result in ice accretion.

Future work planned will include testing the capabilities of the AHMS-IIF to mitigate the switching between the autopilot commands - by using the $A H M S-I I F$ to improve the aircraft flight controller system and the autopilot capabilities for the aircraft. This, for example, the use of the AHMS-IIF to mitigate the switching from airspeed hold at a speed to altitude hold at an altitude according to the environment it is flying in, instead of that presented in Figure 1. This includes a greater understanding on how the autopilot flies the aircraft.

\section{Acknowledgment}

This project is joint-funded by UCLan and Military Air and Information, BAE Systems, UK.

The authors would also like to thank Adam Thornton for his help in gaining a better understanding of X-Plane flight simulator and University of Central Lancashire (UCLan), Centre for Research-informed Teaching for funding Sergio Z. Bayo under the Undergraduate Research Internship Scheme (URIS).

\section{References}

\footnotetext{
${ }^{1}$ University of Loughborough "Implementation of Pilot Authority and Control of Tasks with application to autonomous decision-making for Unmanned Air Vehicles", [Online] Available: http://www.lucasresearch.co.uk/projectsMain/undergraduate/Implementation-of-Pilof-Authority-and-Control-of-Tasks-withapplication-to-autonomous-decision-making-for-Unmanned-Air-Vehicles

${ }^{2}$ Willsky, A.S., "A survey of design methods for failure detection in dynamic systems", Automatica, vol. 12, no. 6, 1976, pp. 601-611.

${ }^{3}$ Chow, E. and Willsky, A., "Analytical redundancy and the design of robust failure detection systems", IEEE Transactions on Automatic Control, vol. 29, no. 7, 1984, pp. 603-614.

${ }^{4}$ Patton, R., "Fault detection and diagnosis in aerospace systems using analytical redundancy," Computing E Control Engineering Journal, vol. 2, no. 3, 1991, pp. 127-136.

${ }^{5}$ Napolitano, M., "A fault tolerant flight control system for sensor and actuator failures using neural networks", Aircraft Design, vol. 3, no. 2, 2000, pp. 103-128.

${ }^{6}$ Napolitano, M., "A fault tolerant flight control system for sensor and actuator failures using neural networks", Aircraft Design, vol. 3, no. 2, 2000, pp. 103-128.

${ }^{7}$ Samy, I., Postlethwaite, I., and Gu, D., "Neural network based sensor validation scheme demonstrated on an unmanned air vehicle (UAV) model," 2008 47th IEEE Conference on Decision and Control, 2008, pp. 1237-1242.

${ }^{8}$ Rong, H.J., Huang, G.B., Sundararajan, N., and Saratchandran, P., "Fuzzy Fault Tolerant Controller for Actuator Failures during Aircraft Autolanding," 2006 IEEE International Conference on Fuzzy Systems, 2006, pp. 1200-1204.

${ }^{9} \mathrm{Kim}, \mathrm{S}$., Choi, J., and Kim, Y., "Fault detection and diagnosis of aircraft actuators using fuzzy-tuning IMM filter," IEEE Transactions on Aerospace and Electronic Systems, vol. 44, no. 3, 2008, pp. 940-952.

${ }^{10}$ Martin, J.C.T., "The Adverse Aerodynamic Effects of Inflight Icing on Airplane Operation", TP 185 - Aviation Safety Letter, [Online] Available: http://www.tc.gc.ca/eng/civilaviation/publications/tp185-1-07-feature-3006.htm

${ }^{11}$ Bureau d'Enquêtes et d'Analyses pour la sécurité de l'aviation civile, "Interim report on the accident on 1 st June 2009 to
} 
the Airbus A330-203 registered F-GZCP operated by Air France flight AF 447 Rio de Janeiro - Paris", 2009, [Online] Available: http://www.bea.aero/docspa/2009/f-cp090601e1.en/pdf/f-cp090601e1.en.pdf

${ }^{12}$ Aviation Safety Network, "Accident description for Austral Lineas Aéreas Flight 2553 to Buenos Aires-Aeroparque", [Online] Available: http://aviation-safety.net/database/record.php?id=19971010-0

${ }^{13}$ NASA, "Ice In or On Static System Cause of X-31 Crash", 1995, [Online] Available: http://www.nasa.gov/centers/ dryden/news/NewsReleases/1995/95-33_pf.html

${ }^{14}$ Janeway, C., Travers, P., Walport, M., Shlomchik, M., Immunobiology: The Immune System in Health and Disease, 6th Ed. Garland Science, 2004.

${ }^{15}$ Mokhtar, M. and Howe, J.M., "Increasing Endurance of an Autonomous Robot using an Immune-Inspired Framework", in Proc. of the 2011 IEEE International Conference on Robotics and Automation (ICRA), 2011.

${ }^{16}$ Greensmith, J., The Dendritic Cell Algorithm, PhD thesis, University Of Nottingham, 2007.

${ }^{17}$ Mokhtar, M., Bi, R., Timmis, J., and Tyrrell, A.M., "A modified dendritic cell algorithm for on-line error detection in robotic systems". IEEE Congress on Evolutionary Computation (CEC) 2009, IEEE Press, 2009, pp. 2055-2062.

${ }^{18}$ de Lemos, R., Timmis, J., Forrest, S., and Ayara, M., "Immune-inspired adaptable error detection for automated teller machines", IEEE Trans. On Systems, Man, And Cybernetics-PartC: Applications and Reviews-Part, vol. 37 pp. 873-886, IEEE Press, 2007.

${ }^{19} \mathrm{X}$-Plane, [Online] Available: http://www.x-plane.com

${ }^{20}$ Timmis, J., Tyrrell, A.M., Mokhtar, M., Ismail, A., Owens, N., and Bi, R., An artificial immune system for robot organisms. Symbiotic Multi-Robot Organisms: Reliability, Adaptability, Evolution, P. Levi and S. Kernbach, Eds, Berlin: Springer-Verlag, 2010, pp. 268-288.

${ }^{21}$ Massart, D.L., Smeyers-Verbeke, J., Caprona, X. and Schlesier, K., "Visual Presentation of Data by Means of Box Plots", Practical Data Handling, LCGC Europe, vol. 18, no. 4, 2005, pp. 215-218.

${ }^{22}$ Airbus A330-243 for X-Plane flight simulator, [Online] Available: http://forums.xplane.org/index.php?app=downloads\&showfile $=11267$

${ }^{23}$ NASA GRC Icing Branch, "A Pilot's Guide to In-Flight Icing", Aircraft Icing Online Courses ES Resources, [Online] Available: http://aircrafticing.grc.nasa.gov/courses_inflight.html 